Michele Mendes ${ }^{\mathrm{a}}$

Jorge Mesquita Huet Machado ${ }^{b}$

Anne Durand ${ }^{\mathrm{C}}$

Isabele Campos Costa-Amaral $^{\mathrm{d}}$

Daniel Valente $^{d}$

Eline Simões Gonçalves ${ }^{d}$

Arline Sydneia Abel Arcuri ${ }^{e}$

Elisabeth Aparecida Trevisan ${ }^{f}$

Paula de Novaes Sarcinelli ${ }^{d}$

Ariane Leites Larentis ${ }^{d}$

Maria Juliana Moura-Correa $\mathrm{g}, \mathrm{h}$

Leiliane Coelho André ${ }^{\mathrm{a}}$

${ }^{\mathrm{a}}$ Universidade Federal de Minas Gerais (UFMG), Faculdade de Farmácia,

Departamento de Análises Clínicas e Toxicológicas. Belo Horizonte, MG, Brasil.

${ }^{b}$ Fundação Oswaldo Cruz (Fiocruz), Diretoria Regional de Brasília. Brasília, DF, Brasil.

C Fundação Oswaldo Cruz (Fiocruz), Diretoria de Recursos Humanos, Coordenação de Saúde do Trabalhador. Rio de Janeiro, RJ, Brasil.

d Fundação Oswaldo Cruz (Fiocruz), Escola Nacional de Saúde Pública Sergio Arouca (ENSP), Centro de Estudos da Saúde do Trabalhador e Ecologia Humana (CESTEH). Rio de Janeiro, RJ, Brasil.

${ }^{\text {e }}$ Fundacentro, Centro Técnico Nacional, Coordenação de Higiene do Trabalho. São Paulo, SP, Brasil.

${ }_{\mathrm{f}}$ Fundacentro, Escritório de Representação de Campinas. Campinas, SP, Brasil.

$\mathrm{g}$ Universidade Federal da Bahia (UFBA). Instituto de Saúde Coletiva (ISC). Programa Integrado em Saúde Ambiental e do Trabalhador (PISAT). Salvador, BA, Brasil.

${ }^{\mathrm{h}}$ Secretaria Municipal de Porto Alegre. Porto Alegre, RS, Brasil.

Contato:

Leiliane Coelho André

E-mail:

leiliane@ufmg.br

Os autores declaram que este trabalho recebeu fomento da SVS/MS (Chamamento Público $n^{\circ}$ 05/2014 - Iniciativas Educacionais Aplicadas à Vigilância em Saúde da Secretaria de Vigilância em Saúde do Ministério da Saúde) e que não há conflitos de interesses.

Os autores informam que este trabalho não é baseado em tese ou dissertação e não foi apresentado em reunião científica.

Recebido: 27/10/2015

Revisado: 27/04/2016

Aprovado: 28/04/2016

\section{Normas ocupacionais do benzeno: uma abordagem sobre o risco e exposição nos postos de revenda de combustíveis}

\author{
Occupational regulation for benzene: an approach on risk and \\ exposure in gas stations
}

\section{Resumo}

Introdução: trabalhadores estão sujeitos a riscos decorrentes da exposição ambiental e ocupacional ao benzeno, situação ainda mais crítica quando associada a fatores como desigualdade social, múltipla exposição, suscetibilidade individual, degradação ambiental e às possíveis interações entre os contaminantes ambientais. Além disso, nem sempre as regulamentações são estabelecidas e/ ou atualizadas apenas a partir de achados científicos, pois são processos permeados por conflitos de interesses. Objetivo: realizar análise crítica sobre a identificação de risco e avaliação da exposição ao benzeno. Métodos: revisão bibliográfica e documental do marco normativo brasileiro e internacional sobre exposição ao benzeno, com relação aos aspectos toxicológicos, de exposição ocupacional e ambiental e de avaliação de risco. Discussão: o controle da exposição ao benzeno permeia o campo da disputa técnico-política de saúde e segurança, constituindo-se em marco regulatório resultante de consenso de entendimentos. Esses entendimentos são marcados pela disputa entre a proteção à saúde e a gestão empresarial das condições de trabalho, em detrimento das evidencias científicas. Em tal contexto, os Limites de Exposição Ocupacional podem variar significativamente entre os países e agências, apesar do reconhecimento universal de que não há limites seguros para exposição ao benzeno, por ser um composto carcinogênico.

Palavras-chave: benzeno; limite de exposição ocupacional; normas regulamentadoras; exposição ambiental; exposição ocupacional.

\begin{abstract}
Introduction: workers are subject to risks from environmental and occupational exposure to benzene. This situation is even more critical when combined with social inequality, multiple exposure, individual susceptibility, environmental degradation, and possible interactions between environmental contaminants. In addition, regulations are not always established and/or updated only from scientific evidences, because they are processes permeated by conflicts of interest. Objective: to produce a critical analysis on risk identification and benzene exposure evaluation. Methods: literature and documentary review of the Brazilian and international regulatory standards on benzene exposure, toxicological aspects, occupational and environmental exposure, and risk evaluation. Discussion: benzene exposure control permeates the technicalpolitical dispute of health and safety, resulting in a regulatory standard from consensus of understandings. These understandings are shaped by the dispute between health protection and business management of working conditions, to the detriment of scientific evidence. In this context, the Occupational Exposure Limits can vary significantly between countries and agencies, despite the universal recognition that there are no safe limits for benzene exposure, because it is a carcinogenic compound.
\end{abstract}

Keywords: benzene; occupational exposure limit; regulatory standards; environmental exposure; occupational exposure. 


\section{Introdução}

Desde o século XVIII, o processo de industrialização introduziu, nos diversos compartimentos laborais e ambientais, grandes quantidades de compostos provenientes das descargas industriais e de várias outras atividades. Como consequência, os trabalhadores estão sujeitos a uma série de riscos decorrentes da exposição ambiental e ocupacional a esses compostos químicos, sendo essa situação ainda mais crítica quando associada a fatores como desigualdade social, múltipla exposição, degradação ambiental e às possíveis interações entre os contaminantes ambientais. Além desses, há fatores que tornam as estruturas de regulamentação frágeis, e cujas normas nem sempre são estabelecidas e/ou atualizadas a partir de achados científicos recentes, mas sim por meio de conflitos de interesses político-sociais-econômicos ${ }^{1}$.

O controle do benzeno no Brasil é marcado pelo processo que culminou na instituição da Comissão Nacional Permanente do Benzeno (CNPBz), em $1995^{2}$, e das comissões estaduais e regionais, em 1997. A dinâmica de sua ação consistiu em vários ciclos decorrentes das movimentações da representação dos trabalhadores, das instituições de saúde e segurança e das empresas, nos quais configuraram períodos de avanços, recuos e de estagnação. Esses períodos também foram marcados pela predominância dos setores industriais envolvidos nesse processo. No final dos anos 1990 e início dos 2000, o setor siderúrgico foi foco de ações para o controle da exposição ao benzeno. Posteriormente, houve uma predominância de adequação do setor petroquímico envolvido na produção do benzeno e, mais recentemente, das refinarias e terminais de transporte de petróleo. Entretanto, apesar da evolução do marco regulatório do período, em relação à restrição da exposição e uso do benzeno que abrangeu um conjunto de ramos produtivos que utilizavam este composto no processo de trabalho, o setor de revenda de combustíveis somente passou a ser incorporado como um ambiente de risco de exposição ao benzeno e monitoramento da saúde e segurança a partir de 2001. Nesse período, iniciativas institucionais de programas de vigilância em saúde voltados para o setor de revenda de combustíveis foram elaboradas e discutidas sistematicamente no âmbito da CNPBz, culminando com a realização do Seminário do Benzeno em Postos de Revenda de Combustíveis, em 2006, na cidade de Curitiba. Esse processo resultou na criação de uma Subcomissão de Postos de Revenda de Combustíveis (PRC), vinculada à $\mathrm{CNPBz}^{3}$.

Em relação à toxicidade do benzeno, ainda permanecem lacunas, especialmente quanto aos mecanismos de ação tóxica e algumas de suas vias de biotransformação que levam ao desenvolvimento das alterações hematológicas e câncer. Diante dessas imprecisões científicas e das evidências em estu$\operatorname{dos}^{4,5}$ que revelam efeitos sobre a saúde em níveis abaixo de $1 \mathrm{ppm}$, torna-se imprescindível que o Brasil atualize a legislação para o monitoramento de ambientes com baixas concentrações de benzeno, como por exemplo no ramo produtivo de revendas de combustíveis, considerando que a gasolina é uma importante fonte de exposição ao benzeno, que deve ser alvo de vigilância. E, também, o necessário aperfeiçoamento e revisão de um conjunto de normas já editadas, como por exemplo a Instrução Normativa $\mathrm{n}^{\mathrm{o}} 1$, sobre avaliação ambiental, aprovada no Acordo Nacional do Benzeno, que também se aplica a PRC.

Este ensaio objetivou realizar uma análise crítica e debater os aspectos orientadores da avaliação da exposição ocupacional ao benzeno e da identificação de risco, sua abrangência e limitações a partir de revisão bibliográfica de legislações e de artigos científicos sobre normas ocupacionais do benzeno. Também se propôs a apresentar um cenário amplo de diversas situações relacionadas à exposição ocupacional ao benzeno, onde se inclui os postos de revenda de combustíveis para os quais, mais recentemente, a vigilância e os trabalhadores passaram a demandar regulamentação relacionada à exposição ao benzeno.

\section{Métodos}

O procedimento metodológico adotado neste ensaio consistiu na revisão bibliográfica e documental e análise crítica do marco normativo brasileiro sobre exposição ocupacional ao benzeno; das normas legais nacional e internacionais sobre os Limites de Exposição Ocupacional; de aspectos toxicológicos do benzeno, de exposição ocupacional e ambiental e de avaliação de risco.

\section{A institucionalização das ações para o controle da exposição ao benzeno no Brasil}

No Brasil, o marco legal que consolida o movimento pelo controle da exposição ao benzeno ocorreu principalmente na década de 1990, tornando-se basilar às demais normas aprovadas nos anos subsequentes. O Quadro 1 apresenta o marco normativo relacionado à exposição ao benzeno, que reflete a evolução das medidas legais no país. Neste período, ações de fiscalizações e estudos ${ }^{6,7}$ evidenciaram importantes revelações de intoxicação por benzeno, que subsidiaram a elaboração dessas normas. 
Quadro 1 - Marco normativo sobre benzeno no Brasil de 1978 a 2016

\begin{tabular}{|c|c|c|c|c|}
\hline Item & Normas & Data & Objeto & Designação \\
\hline 1 & Portaria no 3.214 & 08/06/1978 & $\begin{array}{l}\text { Aprova as NR, Publica o anexo } 13 \text { - Atividades e operações } \\
\text { insalubres. }\end{array}$ & MTE \\
\hline 2 & Portaria $\mathrm{n}^{\circ} 03$ & 28/04/1982 & $\begin{array}{l}\text { Próibe a fabricação de produtos que contenham "benzeno". } \\
\text { Admite a presença de } 1 \% \text { em volume. }\end{array}$ & MTE \\
\hline 3 & Decreto $\mathrm{n}^{\circ} 157$ & 02/07/1991 & $\begin{array}{l}\text { Promulga a Convenção } n^{\circ} 139 \text { da OIT. Prevenção e controle de } \\
\text { riscos causados por agentes cancerígenos. }\end{array}$ & $\begin{array}{l}\text { Presidência da } \\
\text { República }\end{array}$ \\
\hline 4 & Portaria $n^{\circ} 3$ & 10/03/1994 & $\begin{array}{l}\text { Propõe incluir o benzeno enquanto substância cancerígena no } \\
\text { anexo } 13 \text { da NR } 15 .\end{array}$ & MTE \\
\hline 5 & Portaria $\mathrm{n}^{\mathrm{o}} 10$ & 08/09/1994 & Institui o Grupo de Trabalho Tripartite sobre benzeno. & MTE \\
\hline 6 & Decreto $\mathrm{n}^{\circ} 1.253$ & 27/09/1994 & $\begin{array}{l}\text { Promulga a Convenção no } 136 \text { da OIT. Proteção contra riscos } \\
\text { de intoxicação provocados por benzeno. }\end{array}$ & $\begin{array}{l}\text { Presidência da } \\
\text { República }\end{array}$ \\
\hline 7 & Decreto $n^{\circ} 67$ & 04/05/1995 & $\begin{array}{l}\text { Aprova o texto da Convenção } n^{\circ} 170 \text { da OIT, sobre segurança } \\
\text { na utilização de produtos químicos. }\end{array}$ & $\begin{array}{l}\text { Presidência da } \\
\text { República }\end{array}$ \\
\hline 8 & $\begin{array}{l}\text { Acordo Nacional do } \\
\text { Benzeno }\end{array}$ & 28/09/1995 & $\begin{array}{l}\text { Acorda compromissos de restrição da exposição e uso do } \\
\text { benzeno. Constitui a CNPBz e GTBs. }\end{array}$ & $\begin{array}{l}\text { MTE } \\
\text { MS } \\
\text { MPAS }\end{array}$ \\
\hline 9 & Portaria $\mathrm{n}^{\mathrm{o}} 14$ & 20/12/1995 & $\begin{array}{l}\text { Altera o item "Substâncias" para "Substâncias Cancerígenas" } \\
\text { do anexo } 13 \text { da NR } 15 .\end{array}$ & MTE \\
\hline 10 & $\begin{array}{l}\text { Instrução Normativa } \\
n^{\circ} 1\end{array}$ & 20/12/1995 & $\begin{array}{l}\text { Aprova avaliação das concentrações de benzeno em ambientes } \\
\text { de trabalho. }\end{array}$ & MTE \\
\hline 11 & $\begin{array}{l}\text { Instrução Normativa } \\
\text { Intersetorial no } 02\end{array}$ & 20/12/1995 & $\begin{array}{l}\text { Aprova a vigilância da saúde dos trabalhadores na prevenção } \\
\text { da exposição ocupacional ao benzeno. }\end{array}$ & MTE \\
\hline 12 & Portaria $\mathrm{n}^{\circ} 01$ & $18 / 03 / 1996$ & Instala a CNPBz na Fundacentro/SP. & MTE \\
\hline 13 & Portaria $\mathrm{n}^{\circ} 27$ & 08/05/1998 & $\begin{array}{l}\text { Estabelece os prazos para substituição do benzeno na } \\
\text { produção de álcool anidro. }\end{array}$ & MTE \\
\hline 14 & Decreto $\mathrm{n}^{\circ} 2.657$ & 03/07/1998 & $\begin{array}{l}\text { Promulga a Convenção no } 170 \text { da OIT, relativa à Segurança na } \\
\text { utilização de produtos químicos no trabalho. }\end{array}$ & $\begin{array}{l}\text { Presidência da } \\
\text { República }\end{array}$ \\
\hline 15 & Ordem de serviço $n^{\circ} 607$ & 05/08/1998 & $\begin{array}{l}\text { Aprova Norma Técnica sobre Intoxicação Ocupacional/ } \\
\text { Benzeno. Caracteriza benzenismo. }\end{array}$ & MPS \\
\hline 16 & Portaria no 29 & 09/02/1999 & $\begin{array}{l}\text { Regulamenta atividade de distribuição de combustíveis } \\
\text { líquidos e outros combustíveis. }\end{array}$ & ANP \\
\hline 17 & Portaria $n^{\circ} 63$ & 08/04/1999 & $\begin{array}{l}\text { Condiciona anuência prévia da ANP ao fornecimento de } \\
\text { solventes no mercado. }\end{array}$ & ANP \\
\hline 18 & Portaria no 1.339 & 18/11/1999 & Institui a Lista de Doenças relacionadas ao Trabalho, no SUS. & MS \\
\hline 19 & Portaria $\mathrm{n}^{\circ} 72$ & $26 / 04 / 2000$ & $\begin{array}{l}\text { Regulamenta procedimentos ao distribuidor de combustíveis } \\
\text { e outros, para aquisição de gasolina. }\end{array}$ & ANP \\
\hline 20 & Portaria no 248 & $31 / 10 / 2000$ & $\begin{array}{l}\text { Regulamenta controle da qualidade do combustível } \\
\text { automotivo líquido. }\end{array}$ & ANP \\
\hline 21 & Decreto $n^{\circ} 246$ & 28/06/2001 & Ratifica a Convenção 174 da OIT sobre acidentes ampliados. & Poder Legislativo \\
\hline 22 & Portaria no 1969 & 25/10/2001 & $\begin{array}{l}\text { Torna obrigatório no SUS informar o agente causador de } \\
\text { acidentes e doenças do trabalho. }\end{array}$ & MS \\
\hline 23 & Portaria $\mathrm{n}^{\circ} 33$ & 20/12/2001 & $\begin{array}{l}\text { Consulta pública para reduzir o teor máximo de benzeno } \\
\text { em produtos acabados de } 1 \% \text { em volume para } 0,1 \%(v / v) \text {, e de } \\
\text { obrigatoriedade da rotulagem padronizada. }\end{array}$ & MTE \\
\hline 24 & Portaria n ${ }^{\circ} 34$ & $20 / 12 / 2001$ & $\begin{array}{l}\text { Protocolo que determina utilização de indicador biológico de } \\
\text { exposição ocupacional ao benzeno. }\end{array}$ & MTE \\
\hline 25 & Portaria no 309 & $27 / 12 / 2001$ & $\begin{array}{l}\text { Regula especificações das gasolinas, teor do benzeno e } \\
\text { obrigações do controle da qualidade. Integra Regulamento } \\
\text { Técnico } n^{\circ} 5 / 2001 \text {. }\end{array}$ & ANP \\
\hline 26 & Portaria no 310 & $27 / 12 / 2001$ & $\begin{array}{l}\text { Especifica comercialização de óleo diesel e define controle de } \\
\text { qualidade do produto. }\end{array}$ & ANP \\
\hline 27 & Decreto $\mathrm{n}^{\circ} 4.085$ & $15 / 01 / 2002$ & $\begin{array}{l}\text { Promulga a Convenção no } 174 \text { da OIT e a Recomendação } \\
n^{\circ} 181 \text { sobre a Prevenção de Acidentes Industriais Maiores. }\end{array}$ & $\begin{array}{l}\text { Presidência da } \\
\text { República }\end{array}$ \\
\hline
\end{tabular}

(Continua) 
Quadro 1 Continuação...

\begin{tabular}{|c|c|c|c|c|}
\hline 28 & Portaria $\mathrm{n}^{\circ} 05$ & $21 / 03 / 2002$ & $\begin{array}{l}\text { Prorroga prazo para reduzir o teor de benzeno em produtos } \\
\text { acabados de } 1 \%(\mathrm{v} / \mathrm{v}) \text { para } 0,1 \%(\mathrm{v} / \mathrm{v}) \text {. }\end{array}$ & MTE \\
\hline 29 & Nota Técnica nº 07 & $12 / 09 / 2002$ & $\begin{array}{l}\text { Abrangência do campo de aplicação do acordo e legislação do } \\
\text { benzeno. }\end{array}$ & MTE \\
\hline 30 & Resolução no 252 & $16 / 09 / 2003$ & $\begin{array}{l}\text { Proíbe produtos que contenham o benzeno em sua } \\
\text { composição, admitida a presença de } 0,1 \%(\mathrm{v} / \mathrm{v}) \text {. }\end{array}$ & $\begin{array}{l}\text { Agencia Nacional de } \\
\text { Vigilância Sanitária } \\
\text { (Anvisa)/MS }\end{array}$ \\
\hline 31 & $\begin{array}{l}\text { Portaria Interministerial } \\
n^{\circ} 775\end{array}$ & $28 / 04 / 2004$ & $\begin{array}{l}\text { Estabelece prazos para redução da concentração de } 0,8 \% \text { a } \\
0,1 \%(\mathrm{v} / \mathrm{v}) \text { de benzeno em produtos acabados. Para combustíveis } \\
\text { admite } 1 \%(\mathrm{v} / \mathrm{v}) \text {. }\end{array}$ & MS/MTE \\
\hline 32 & Portaria n ${ }^{\circ} 776$ & $28 / 04 / 2004$ & $\begin{array}{l}\text { Regulamenta procedimentos relativos à vigilância da saúde } \\
\text { dos trabalhadores expostos ao benzeno. }\end{array}$ & MS \\
\hline 33 & Portaria n ${ }^{\circ} 777$ & $28 / 04 / 2004$ & $\begin{array}{l}\text { Dispõe sobre procedimentos para notificação compulsória de } \\
\text { agravos à saúde do trabalhador no SUS. Inclui exposição ao } \\
\text { benzeno. }\end{array}$ & MS \\
\hline 34 & Nota Técnica no 30 & $23 / 11 / 2004$ & $\begin{array}{l}\text { Revisa o capítulo V do Acordo Nacional do Benzeno - Da } \\
\text { participação dos Trabalhadores. }\end{array}$ & MTE \\
\hline 35 & $\begin{array}{l}\text { Instrução Normativa } \\
n^{\circ} 1\end{array}$ & 07/03/2005 & $\begin{array}{l}\text { Define competências da União, estados, municípios na área de } \\
\text { vigilância em saúde ambiental para prevenção e controle de } \\
\text { fatores de risco. Inclui exposição ao benzeno. }\end{array}$ & MS/SVS \\
\hline 36 & Portaria no 207 & $11 / 03 / 2011$ & $\begin{array}{l}\text { Procedimentos de cadastramento das empresas usuárias de } \\
\text { benzeno. }\end{array}$ & MTE \\
\hline 37 & Portaria no 252 & $04 / 08 / 2011$ & $\begin{array}{l}\text { Constitui a Subcomissão de Postos Revendedores de } \\
\text { Combustíveis }\end{array}$ & MTE \\
\hline 38 & Portaria n ${ }^{\circ} 57$ & 20/10/2011 & $\begin{array}{l}\text { Regula especificações das gasolinas e teor de benzeno. Revoga } \\
\text { a Res. } 309 \text { (2011). }\end{array}$ & ANP \\
\hline 39 & Portaria no 291 & $08 / 12 / 2011$ & $\begin{array}{l}\text { Altera o anexo 13-A (Benzeno) da NR } 15 \text { - Atividades e } \\
\text { Operações Insalubres (NR } 7 \text { e NR 9). }\end{array}$ & MTE \\
\hline 40 & Portaria no 308 & 29/02/2012 & $\begin{array}{l}\text { NR } 20 \text { - Segurança e saúde no Trabalho com inflamáveis e } \\
\text { combustíveis. }\end{array}$ & $\begin{array}{c}\text { Secretaria de } \\
\text { Inspeção do } \\
\text { Trabalho (SIT)/MTE }\end{array}$ \\
\hline 41 & Resolução $n^{\circ} 40$ & $25 / 10 / 2013$ & $\begin{array}{l}\text { Regula especificações das gasolinas e teor de benzeno. Revoga } \\
\text { a Res. } 57 \text { (2011). }\end{array}$ & ANP \\
\hline 42 & Resolução nº41 & $05 / 11 / 2013$ & $\begin{array}{l}\text { Atualiza arcabouço legal dos PRC. Institui as Instalações de } \\
\text { Abastecimento de Combustíveis como campo de aplicação de saúde } \\
\text { e segurança. }\end{array}$ & ANP \\
\hline 43 & Resolução no 57 & $17 / 10 / 2014$ & $\begin{array}{l}\text { Atualiza arcabouço legal dos PRC. Altera a Resolução } 41 \\
\text { (2013). }\end{array}$ & ANP \\
\hline 44 & Portaria no 1.109 & 21/09/2016 & $\begin{array}{l}\text { Aprova o anexo } 2 \text { - Exposição Ocupacional ao Benzeno em } \\
\text { Postos Revendedores de Combustíveis (PRC), } \\
\text { da NR } 9 \text { - Programa de Prevenção de Riscos Ambientais (PPRA). }\end{array}$ & MTE \\
\hline
\end{tabular}

Fonte: Atualizado a partir da sistematização de Corrêa ${ }^{92}$. Consulta às bases de dados da Agência Nacional do Petróleo (ANP), Ministério do Trabalho e Emprego (MTE), Ministério da Previdência e Assistência Social (MPAS), Ministério da Previdência Social (MPS), Ministério da Saúde (MS), Organização Internacional do Trabalho (OIT).

Dentre elas, destaca-se a efetivação do Acordo Nacional do Benzeno ${ }^{2}$, firmado em 20 de dezembro de 1995, que estabeleceu pactuação tripartite para implementação de medidas de restrição da exposição e do uso do benzeno em diversos processos produtivos no país. O acordo instituiu a CNPBz e os Grupos de Representação dos Trabalhadores do Benzeno (GTB), instância participativa por local de trabalho, responsáveis pelo acompanhamento das medidas desencadeadas pelo marco normativo. A CNPBz foi inicialmente composta pelos representantes do Governo à época (Ministério do Trabalho; Ministério da Saúde; Ministério da Previdência e Assistência Social e Ministério da Indústria, Comércio e Turismo), dos trabalhadores (Centrais Sindicais, Central Única dos Trabalhadores (CUT) e Força Sindical) e dos empregadores: Instituto Brasileiro de Siderurgia (IBS); Sindicato das Indústrias de Produtos Químicos para Fins Industriais e da Petroquímica no Estado de São Paulo (Simproquim); Instituto Brasileiro de Petróleo, Gás e Biocombustíveis (IBP); Petrobras; Confederação Nacional da Indústria (CNI) e Associação Brasileirada Indústria Química (Abiquim). 
Mais recentemente foi identificada a urgência em organizar medidas de controle das exposições ocupacionais, na distribuição e comercialização de combustíveis. Dessa forma, foi criada a Subcomissão de PRC, em 2011, pela Portaria ${ }^{\circ} 252^{3}$.

No âmbito da CNPBz, permanece a discussão contínua em relação à normatização da exposição ao benzeno nos setores produtivos e na revenda de combustíveis, tendo como referência a adoção do Valor de Referência Tecnológico (VRT) estabelecido em 1994 em substituição ao Limite de Tolerância (LT). O VRT para o benzeno é definido na Norma Regulamentadora 15 (NR 15) ${ }^{8}$ como:

a concentração de benzeno no ar considerada exequível do ponto de vista técnico, definido em processo de negociação tripartite. VRT deve ser considerado como referência para os programas de melhoria contínua das condições dos ambientes de trabalho. O cumprimento do VRT é obrigatório e não exclui risco à saúde.

Os valores adotados correspondem a 2,5 ppm para as indústrias siderúrgicas; e 1,0 ppm para as químicas e petroquímicas. Essa abordagem foi considerada um avanço na regulação do benzeno e na busca por melhorias contínuas da exposição nos ambientes de trabalho que visam à proteção à saúde do trabalhador, em contraposição à simples definição de um limite seguro de exposição, que não existe, por se tratar de um carcinógeno. $\mathrm{O}$ anexo 13-A da NR 15, referente às atividades e operações insalubres, regulamenta ações, atribuições e procedimentos de prevenção à exposição ocupacional ao benzeno, para a proteção da saúde do trabalhador. Esse anexo se aplica a "todas as empresas que produzem, transportam, armazenam, utilizam ou manipulam benzeno e suas misturas líquidas contendo 1\% (um por cento) ou mais de volume e aquelas por elas contratadas, no que couber".

É importante ressaltar que as normas referentes ao controle da exposição ocupacional ao benzeno, estabelecidas a partir do acordo de 1995, não abrangiam as atividades de armazenamento, transporte, distribuição, venda e uso de combustíveis derivados de petróleo. Apesar do Acordo do Benzeno prever, como atribuição da $\mathrm{CNPBz}^{9}$, a possibilidade de incluir ou alterar dispositivos legais para regulamentar a prevenção da exposição ocupacional ao benzeno, isso somente se iniciou com a instalação da subcomissão de PRC da CNPBz, em 2011. Entre as medidas, ocorreu a alteração da Norma Regulamentadora 20 (NR 20), em $2012^{10}$, que instituiu procedimentos e controles operacionais para a extração, armazenagem, transporte, manuseio e manipulação de líquidos combustíveis, inflamáveis e gás de petróleo. Em 2014, foi proposta a inclusão do anexo 2 na Norma Regulamentadora 9 (NR 9), que estabelece os requisitos mínimos de segurança e saúde no trabalho para as atividades com exposição ocupacional ao benzeno em PRC ${ }^{11}$. Consenso sobre essa norma foi apenas alcançado em 2016 na CNPBz. A incorporação dos PRCs ao marco legal normativo relacionado à exposição ao benzeno é uma discussão que se coloca neste momento, que abrange posições distintas sobre a necessidade de aplicação dessas leis a esse ramo produtivo, as especificidades do processo de trabalho, bem como a adequação dos processos de monitoramento ambiental e biológico. Entretanto, apesar das divergências de posições, esse movimento representa um importante passo para o avanço da legislação vigente, no sentido de ampliar as ações de prevenção da exposição ao benzeno aos trabalhadores de PRC.

\section{Os postos de revenda de combustíveis como fonte de exposição ao benzeno}

A gasolina é um derivado do petróleo que contêm hidrocarbonetos alifáticos e aromáticos, dos quais um dos compostos é o benzeno, com a concentração de até $1 \%$, e por isso é uma importante fonte de exposição ocupacional e ambiental. A expansão da frota de veículos automotivos e do consumo de gasolina nos centros urbanos aumenta a magnitude dessa exposição. Estima-se que, por meio das emissões dos veículos automotores, as concentrações desse poluente no ar podem alcançar $100 \mathrm{ppb}$ nos centros urbanos com elevado tráfego ${ }^{12,13}$. No Brasil, a Agência Nacional do Petróleo (ANP) estabeleceu, por meio da Resolução ${ }^{\circ} 40$, de 25 de outubro de $2013^{14}$, atualização quanto às especificações das gasolinas para a comercialização e as obrigações dos agentes econômicos sobre o controle da qualidade do produto. No entanto, a partir da produção de gasolinas aditivadas com maior octanagem, a quantidade de benzeno presente é maior em relação aos outros tipos de gasolina. Dessa forma, a ANP, por meio desse regulamento técnico, determinou o valor máximo de concentração de benzeno de $1 \%(\mathrm{v} / \mathrm{v})$, na gasolina do tipo C ou Premium tipo C, e também dos teores para outros hidrocarbonetos aromáticos e olefínicos presentes na gasolina (Tabela 1).

As atividades relacionadas aos PRCs envolvem diferentes processos de trabalho, como abastecimento, troca de óleo, lavagem de veículo, recebimento de caminhão-tanque, análise de amostras-controle da gasolina, revenda de mercadorias, entre outras, para as quais são necessárias medidas de gestão ambiental e ocupacional, no intuito de se evitar a ocorrência de impactos ao meio ambiente, à saúde do trabalhador e da população do entorno. Nesse aspecto, assim como as normas relacionadas ao controle das exposições nos ambientes de trabalho e proteção à saúde do trabalhador, é também de fundamental importância o marco regulatório para o controle das contaminações ambientais por exposição ao benzeno, abrangendo a população em geral. 
Tabela 1 Especificação dos teores de benzeno e hidrocarbonetos na gasolina

\begin{tabular}{|c|c|c|c|}
\hline \multirow[b]{2}{*}{ Característica } & \multirow[b]{2}{*}{ Unidade } & \multicolumn{2}{|c|}{ Especificação } \\
\hline & & $\begin{array}{c}\text { Gasolina comum } \\
\text { Tipo } C^{a}\end{array}$ & $\begin{array}{c}\text { Gasolina Premium } \\
\text { Tipo } C^{a}\end{array}$ \\
\hline Benzeno, máx. b & $\%$ volume & 1,0 & 1,5 \\
\hline Hidrocarbonetos aromáticos, máx.b,c & $\%$ volume & 45 & 45 \\
\hline Hidrocarbonetos olefínicos, máx. b,c & $\%$ volume & 30 & 30 \\
\hline
\end{tabular}

Fonte: Resolução ANP n ${ }^{\circ}$ 40, de 25 de outubro de $2013^{14}$.

${ }^{a}$ Existem duas classificações de gasolina automotiva comercializadas no Brasil: A (Premium ou Podium, dependendo do fabricante) e C (gasolina comum e aditivada), ambas com misturas de diferentes tipos de hidrocarbonetos. Gasolina A é a produzida no país, sendo importada ou formulada pelos agentes econômicos autorizados para cada caso, isenta de componentes oxigenados e que atenda à Resolução da ANP ${ }^{14}$; gasolina C é constituída de gasolina $\mathrm{A}$ e etanol anidro combustível, nas proporções e especificações definidas pela legislação em vigor e que atenda à Resolução da ANP14. A gasolina aditivada possui adição de detergentes e dispersantes à sua composição, que promovem limpeza do sistema de alimentação do veículo, incluindo bicos injetores e válvulas de admissão, enquanto a gasolina comum não possui esses detergentes especiais. As gasolinas Premium ou Podium, de alto Índice Antidetonante (IAD), além de conterem os detergentes que a gasolina aditivada possui, também apresentam maior octanagem, permitindo melhor aproveitamento do potencial do motor.

${ }^{b}$ Os teores máximos de enxofre, benzeno, hidrocarbonetos aromáticos e hidrocarbonetos olefínicos devem ser atendidos após a adição de etanol anidro combustível à gasolina $\mathrm{A}$, no teor de um ponto percentual abaixo do valor em vigor na data da produção da gasolina.

${ }^{\mathrm{C}}$ Alternativamente à certificação de adição de produtos na gasolina, é permitido o uso de cromatografia gasosa para determinação dos hidrocarbonetos aromáticos e olefínicos. Em caso de desacordo entre resultados, prevalecerão os valores determinados pelo ensaio realizado conforme a norma ABNT NBR 14932 ou ASTM D1319.

A contaminação ambiental é considerada um crime ambiental federal, referendada pelo Decreto $\mathrm{n}^{\mathrm{o}} 6.514$, de $2008^{15}$, que regulamenta a Lei Federal 9.605/1998, responsável pela definição das infrações. Muitas dessas legislações estão relacionadas a medidas preventivas de acidente e/ou impacto do processo produtivo sobre o meio ambiente, a partir de cumprimento de dispositivos legais. Dentre elas, por exemplo, o funcionamento dos PRCs, por envolver atividades de riscos com potencial de vazamentos e emissões de vapores de solventes, requer a aplicação de estudos e licenças, exigidas pelo órgão ambiental estadual competente ou do Instituto Brasileiro do Meio Ambiente e dos Recursos Naturais Renováveis (Ibama), em caráter supletivo, por meio de um Estudo de Impacto Ambiental (EIA) e um Relatório de Impacto Ambiental (RIMA). Além desses estudos, o estabelecimento precisa de Licença Prévia (LP), Licença de Instalação (LI) e da Licença de Operação (LO), obrigatórias para seu funcionamento ${ }^{16}$.

Ainda, no que se refere à prevenção de acidente ambiental, a resolução CONAMA $n^{0} 273^{17}$ representa importante avanço na medida em que determina a localização dos PRCs a uma distância mínima de $100 \mathrm{~m}$ das residências. Outra resolução ${ }^{18}$ abrange avaliação quanto à conformidade e manutenção dos equipamentos e sistemas destinados ao armazenamento, distribuição de combustíveis, montagem e instalação, definindo que estas devem ser avaliadas no âmbito do Sistema Brasileiro de Avaliação da Conformidade, com periodicidade não superior a cinco anos. Além disso, a Associação Brasileira de Normas Técnicas
(ABNT) estabelece que os PRCs devem instalar poços de monitoramento com a finalidade de verificar vazamentos e/ou contaminantes em fase livre ou dissolvidos na água subterrânea, independentemente da profundidade do lençol freático (NBR 13.786:2014) ${ }^{19}$.

As atividades que envolvem a exposição dos trabalhadores aos riscos relacionados à exposição aos solventes presentes nos combustíveis, em especial ao benzeno presente na gasolina, constituem-se como uma grande preocupação para o campo da Saúde do Trabalhador. Além das atividades relacionadas ao armazenamento e manuseio de líquidos inflamáveis serem classificadas como perigosas, a exposição crônica ao benzeno possui grande relevância toxicológica, sendo preconizada a recuperação dos vapores e, subsidiariamente, o monitoramento ambiental e biológico. Trabalhadores de PRCs e outros trabalhadores que utilizam produtos químicos inflamáveis foram contemplados, em 2012, com a nova redação da NR $20^{20}$, que estabeleceu requisitos mínimos para a gestão de segurança e saúde no trabalho a riscos provenientes de atividades de extração, produção, armazenamento, transferência, manuseio e manipulação de inflamáveis e líquidos combustíveis. A partir dessa revisão, as instalações foram diferenciadas e classificadas em três classes, em função da atividade e quantidade de inflamáveis e combustíveis armazenados e das medidas de segurança necessárias para cada tipo.

Dessa forma, em 2014, impôs-se a necessidade de aperfeiçoamento e atualização da NR $9^{11}$, junto à Subcomissão de PRC da CNPBz, com a proposição de incluir o anexo 2, sob o título de "Exposição 
Ocupacional ao Benzeno em Instalações de Abastecimento de Combustíveis". Dentre os catorze itens que compõem o anexo, apenas recentemente aprovado (21/09/2016), destacam-se: 1) como campo de aplicação de requisitos para saúde e segurança no trabalho em PRC, sendo considerado como "o estabelecimento localizado em terra firme que revende, a varejo, combustíveis automotivos e abastece tanque de consumo dos veículos automotores terrestres ou em embalagens certificadas pelo Instituto Nacional de Metrologia, Qualidade e Tecnologia (INMETRO).”21; 2) Programa de Controle Médico de Saúde Ocupacional (PCMSO), que explicita que os trabalhadores que exercem atividades de riscos de exposição ao benzeno devem realizar, com frequência mínima semestral, hemograma completo com contagem de plaquetas e reticulócitos, independente de outros exames; 3) Programa de Prevenção de Riscos Ambientais (PPRA), que aplica as disposições da NR 9 aos PRCs, referendando que o documento base deve conter explicitamente o reconhecimento de todas as atividades, setores, áreas, operações, procedimentos e equipamentos onde possa ocorrer exposição dos trabalhadores a combustíveis contendo benzeno, seja pelas vias respiratória, cutânea ou digestiva, dentre outros dispositivos de proteção à saúde, segurança e informação de riscos da exposição ao benzeno; 4) Controle Coletivo de Exposição durante o abastecimento, indicando que os PRCs devem instalar sistema de recuperação de vapores; e 5) detalhamento de diversas atividades operacionais, tais como a determinação de que todas as bombas de abastecimento de combustíveis líquidos contendo benzeno devem estar equipadas com bicos automáticos, e que fica vedado enchimento de tanques veiculares após o desarme do sistema automático, exceto quando ocorrer o desligamento precoce do bico, em função de características do tanque do veículo.

\section{Contexto sóciotécnico da avaliação do risco}

A avaliação da exposição aos compostos químicos constitui um fator determinante das condições de saúde e vigilância para a Saúde Pública, dada a necessidade de minimizar os efeitos de tais exposições, com magnitudes que variam de alterações potencialmente reversíveis até a morte. Diversos compostos químicos se destacam pelo potencial tóxico que apresentam nas interações com os organismos vivos e, entre elas, destaca-se o benzeno. De acordo com a Agência Internacional de Pesquisa sobre o Câncer (IARC) ${ }^{22}$, desde 1982, o benzeno foi classificado como um agente carcinogênico para a espécie humana (Grupo 1), o que significa que não há limite seguro de exposição. Diante dessa evidência, espera-se dos países, incluindo o Brasil, legislação específica e ações reguladoras que tenham como objetivo minimizar o risco à saúde das populações expostas, ocupacional ou ambientalmente.

O conhecimento da exposição, incluindo as exposições a baixas concentrações, e dos seus efeitos sobre a saúde, empregando avaliações ambientais e análises de indicadores biológicos de exposição, permite acompanhar situações de riscos, para as quais se considera não haver limites seguros para exposição a carcinógenos. Sua importância deve-se à possibilidade de intervenção, a partir da posse desses dados, para estabelecer prioridades e formas de ações efetivas para proteger as populações sob risco. Sendo assim, é importante conhecer a solidez e as limitações dos dados toxicológicos, que são dependentes da disponibilidade e aplicação de técnicas analíticas sensíveis e precisas, assim como métodos adequados para o desenvolvimento de estudos experimentais e de biomonitoramento das populações expostas.

No monitoramento biológico, é estimado o risco para a saúde dos indivíduos com base na exposição a partir da resposta produzida no sistema biológico dos trabalhadores (dose interna), o que possibilita detectar precocemente uma exposição excessiva e/ ou alguma alteração biológica reversível. Para estabelecimento de padrões de concentração permissíveis, valores de Limites de Exposição Ocupacional (LEO) são estimados pela média ponderada de concentração de um composto tóxico pelo tempo de jornada de trabalho. Contudo, há ressalvas na literatura ${ }^{23}$ de que esses parâmetros devem ser aplicados a partir dos conhecimentos atuais, evidenciando a temporalidade, a quantidade de dados disponíveis e os métodos empregados nas estimativas das incertezas, que devem ser explicitados nas recomendações de uso dos LEOs, bem como nas diferentes situações de exposição aguda e crônica.

É importante destacar que, para os agentes reconhecidamente carcinogênicos e genotóxicos, dentre os quais o benzeno, não há limites seguros de exposição. Portanto, esses conceitos são desafiados e dúvidas são expressas quanto à aceitabilidade de qualquer limite de exposição acima de zero. Isso requer uma constante reavaliação das prioridades para tomadas de decisão e para aplicação destes LEOs, que precisam ser reavaliados periodicamente para reafirmar ou para alterar os valores-limite.

Além disso, um LEO para um mesmo composto pode variar significativamente entre os países e as diferentes agências de normatização. Para a identificação de expostos, na avaliação de risco, preconiza-se, para o Brasil, a definição de exposição ocupacional, conceituada conforme a Portaria MS nº 776, de 28 de abril de $2004^{24}$, que define como exposição aquela 
decorrente de atividades laborais em níveis acima dos observados em exposições populacionais. E, quando esses dados não estão disponíveis, devem ser utilizados os padrões de exposição encontrados na literatura científica.

\section{Aspectos toxicológicos do benzeno}

Devido às suas características físico-químicas, o benzeno é facilmente absorvido por via oral, dérmica e pulmonar, sendo as duas últimas as mais relevantes. O benzeno, uma vez absorvido, é distribuído para diversos órgãos e sistemas do organismo, e maiores concentrações são observadas em tecidos ricos em lipídios ${ }^{25}$.

A biotransformação do benzeno é bastante complexa e ocorre principalmente no fígado e, em menor proporção, no pulmão e na medula óssea. Apesar da complexidade, sua compreensão é de grande importância, uma vez que vários estudos demonstraram que os efeitos tóxicos do benzeno advêm de seus metabólitos. Os mecanismos associados aos efeitos tóxicos e carcinogênicos do benzeno ainda não foram completamente esclarecidos, no entanto, é conhecido que sua toxicidade é dependente da biotransformação ${ }^{26}$. Um fator relevante em relação à biotransformação do benzeno é que, em exposições a baixas concentrações, o benzeno pode ser metabolizado por duas vias metabólicas. Sendo assim, a produção desses metabólitos com atividade tóxica poderia levar a efeitos tóxicos maiores do que o esperado em indivíduos expostos a baixas concentrações do benzeno no ar, especialmente naqueles susceptíveis $^{27}$.

Os principais efeitos tóxicos do benzeno sobre a saúde humana ocorrem por sua ação mutagênica e carcinogênica. Os sinais e sintomas presentes na intoxicação aguda decorrem da ação sobre o sistema nervoso central. Estudos em animais sugerem uma redução da atividade elétrica do cérebro, o que produz perda de reflexos, tremores, narcose e morte. Soma-se a esse quadro a ação irritante do benzeno sobre as mucosas oculares e respiratórias ${ }^{25}$. Na exposição crônica são observados agravos à saúde relacionados a distúrbios leucêmicos, linfoproliferativos, além de desordens quantitativas de células sanguíneas, mesmo em concentrações inferiores a $1 \mathrm{ppm}^{4,28}$. A exposição a esse hidrocarboneto por período prolongado está associada à hipoplasia medular, que acarreta citopenias, como leucopenia, trombocitopenia e eritropenia. Além disso, pode ocorrer pancitopenia, que se refere à redução de todas as linhagens hematológicas ${ }^{29}$. Esse efeito pode ser reversível dependendo da extensão da lesão; e, com o fim da exposição e assistência médica adequada, os parâmetros hematológicos podem retornar aos níveis normais. No entanto, pode permanecer uma sensibilidade medular e por isso não deve ocorrer exposição a qualquer agente mielotóxico ${ }^{30}$. Nos casos em que a reversibilidade não ocorra, há o aparecimento da aplasia da medula, sendo necessário o transplante do órgão ${ }^{25}$.

Estudos sobre exposição ao benzeno e o aparecimento da leucemia mieloide aguda apresentam evidências científicas, as quais não deixam dúvidas em relação ao nexo causal; também demonstram evidências de que a exposição ao benzeno no trabalho aumenta o risco de leucemia. Khalade et al. ${ }^{31}$, em um estudo de meta-análise, utilizou modelo de efeitos fixos e aleatórios, com o qual estimou o Risco Relativo em 1,40 (IC95\%: 1,23-1,57), efeito sumário ponderado para as leucemias (leucemia mieloide aguda, leucemia linfocítica aguda, leucemia linfocítica crônica) associadas com exposição cumulativa a baixas concentrações de benzeno. No entanto, para alguns efeitos mielotóxicos, como a associação entre doenças mieloproliferativas e leucemia mieloide crônica, os estudos são escassos e controversos. Embora Glass et al. ${ }^{32}$ não tenham identificado associação entre doenças mieloproliferativas e leucemia mieloide crônica e exposição a baixas concentrações de benzeno, em outro estudo, de Schnatter et al. ${ }^{33}$, conduzidos no Canadá, Reino Unido e Austrália, ficou evidenciado risco aumentado para síndrome mielodisplásica e doenças mieloproliferativas. Schnatter et al. $^{33}$ também destacaram que a incidência de síndrome miolodisplásica aumenta à medida que o diagnóstico e a classificação da doença se tornam mais comuns e quando é possível a realização de estudos epidemiológicos em grande populações.

Importante destacar que a identificação da exposição ao benzeno e seus efeitos à saúde passa por considerar que o diagnóstico de benzenismo, conjunto de sinais e sintomas decorrentes da exposição ocupacional ao benzeno, é eminentemente clínico e epidemiológico, fundamentando-se na história de exposição ocupacional e na observação de sintomas e sinais clínicos e laboratoriais ${ }^{7}$.

\section{Avaliação da exposição ocupacional ao benzeno}

Existem entendimentos distintos sobre o real significado do que seja a exposição ao benzeno e de quais são as situações que configuram relações potenciais de causalidade e de risco. No âmbito da exposição ao benzeno nos postos de combustíveis, ainda existem dificuldades em relação às evidências a partir de recortes que levem em consideração a real exposição e consequentemente, a construção de grupos controles que permitam a comparação dos efeitos 
relacionados a diferentes gradientes de exposição, considerando tratar-se de uma exposição ubíqua.

Na década de 1990, estudos realizados na China mostraram que a média de exposição ao benzeno chegava até 90 ppm; nos anos 2000, a média relatada foi de $21 \mathrm{ppm}^{34-36}$. Estudos mais recentes apontam para uma redução dos níveis de exposição nos diversos processos produtivos, em torno ou abaixo de $1 \mathrm{ppm}$. Ao longo dos anos ocorreram mudanças tecnológicas nos ambientes de trabalho, a partir da redução dos LEO, que foram estabelecidos devido às evidências toxicológicas da exposição e da carcinogenicidade do benzeno. Entretanto, a China ainda estabelece um limite de $2 \mathrm{ppm}$ (valor abaixo apenas de Taiwan, que é de $5 \mathrm{ppm}$ ), sendo mais elevado quando comparado ao de outros países. Existem relatos de equipamentos de proteção individual não utilizados ou com uso indevido em diferentes indústrias e países ${ }^{37-41}$.

Com referência à indústria de calçados em Portugal, o benzeno não é reportado como um dos principais compostos medidos no ambiente de traba$l_{\text {ho }}^{39}$, o que comprova a possibilidade de substituição tecnológica do benzeno nesse tipo de indústria, assim como ocorreu em diversos outros países, incluindo o Brasil. Na cadeia produtiva do petróleo, estudos na Austrália apontaram concentrações de benzeno nas áreas críticas de 1,28 a $1,74 \mathrm{ppm}^{40}$. Estudos identificaram exposições ocupacionais ao benzeno em menores concentrações, tais como 0,51 ppm para mecânicos no Brasil ${ }^{41}$, e em torno de 90 ppb em refinaria na Índia ${ }^{42}$ e em mina de carvão na Estônia ${ }^{43}$. Outros processos produtivos, como o setor de fotocópias em Taiwan, apresentou valores de exposição ao benzeno entre 6 e 62 ppb, chegando a 1,24 $\mathrm{ppm}^{44,45}$ e variando de acordo com o modo de operação. Em estudo americano sobre processo de trabalho com limpeza de peças metálicas empregando solventes contendo até $58 \mathrm{ppm}$ de benzeno, as concentrações de benzeno no ar não excederam o limite de exposição ocupacional de $0,5 \mathrm{ppm}(8 \mathrm{~h}$ TWA - Time Weighted Average $)^{46}$. A exposição ao benzeno em um hospital da China foi avaliada por Lü et al. ${ }^{47}$, cujos resultados evidenciaram uma baixa concentração (na ordem de 9 ppb).

Na Europa, o projeto PEOPLE ${ }^{48}$ avaliou a exposição ao benzeno em seis cidades, em diferentes tipos de ambientes, e uma das maiores concentrações foi verificada no interior de táxis, devido à proximidade de fontes emissoras, levando a uma exposição ocupacional de taxistas. A concentração de benzeno no interior de veículos foi medida em Bruxelas $(27,5 \mu \mathrm{g} /$ $\mathrm{m}^{3}$ ou $\left.8,5 \mathrm{ppb}\right)$ e Madri $\left(14,8 \mu \mathrm{g} / \mathrm{m}^{3} \text { ou } 4,6 \mathrm{ppb}\right)^{48}$.

A exposição ao benzeno associada a efeitos hematotóxicos foi investigada por Schnatter et al. ${ }^{49}$, em um estudo que avaliou doze índices sanguíneos em
928 trabalhadores de cinco fábricas em Xangai, na China, cuja exposição individual média ao benzeno foi de $7,4 \mathrm{mg} / \mathrm{m}^{3}$ (2,3 ppm). Os neutrófilos e o volume plaquetário médio (VPM) foram os parâmetros mais sensíveis a exposições de 7,8-8,2 ppm, sendo que a redução na contagem de hemácias e hemoglobina e o aumento do volume corpuscular médio (VCM) foram mais afetados nas exposições associadas a concentrações a partir de $10 \mathrm{ppm}$.

Avaliações de exposição ocupacional em PRC são limitadas pelo número de países que ainda têm atendentes: trabalhos na literatura indicam exposição individual a benzeno ( $8 \mathrm{~h}$ TWA) de $1,7 \mathrm{mg} / \mathrm{m}^{3}$ (em torno de 0,5 ppm) em Roma ${ }^{50}$ e 0,37 ppm para frentistas no Rio de Janeiro ${ }^{41}$.

Em síntese, fica evidenciado que, dependendo do setor de trabalho, a exposição ao benzeno pode variar consideravelmente, como apresentado nos diferentes estudos de vários países. Apesar da grande variação da exposição ocupacional evidenciada, assim como sua oscilação temporal, os dados provenientes desses estudos contribuem para a identificação dos grupos de riscos ocupacionais prioritários e para implementar políticas de promoção e proteção à saúde dos trabalhadores e constituem as bases referenciais para o estabelecimento de normas ocupacionais.

\section{Normatização da exposição ocupacional ao benzeno}

Estabelecer os Limites de Exposição Ocupacional (LEO) para os riscos presentes no local de trabalho é um dos objetivos das políticas públicas para a proteção da saúde dos trabalhadores ao longo dos anos, os quais são definidos por instituições governamentais no âmbito dos países. Normalmente, os LEOs são utilizados para orientar os profissionais de saúde na avaliação e controle da exposição e dos riscos nos locais de trabalho. A definição desses limites fundamenta-se na avaliação toxicológica, nos estudos epidemiológicos e clínicos, além dos testes toxicológicos preditivos, resultando em relações de dose-resposta ${ }^{51}$. A abordagem tradicional tem sido a de recomendar LEO por especialistas a partir das evidências científicas disponíveis e definir os níveis de concentrações, principalmente com base em considerações relacionadas à saúde. Agências e organismos internacionais estabelecem as recomendações a partir dessas evidências. Nos Estados Unidos, por exemplo, a ACGIH (American Conference of Governmental Industrial Hygienists) recomenda os LEOs para os compostos químicos encontrados em exposições ocupacionais, cujos limites são revisados a cada dois anos ${ }^{50}$ a partir dessas evidências científicas. 
No entanto, os acordos para estabelecimento desses limites sofrem influências de interesses político-econômicos, o que resulta por vezes em adoção de parâmetros defasados e distantes de um padrão sanitário e nem sempre estes são baseados em considerações científicas e/ou evidências dos impactos à saúde.

Os sistemas de determinação dos LEOs não são normalizados e mostram-se divergentes em todo o mundo, embora alguns processos de harmonização em um contexto global tenham sido iniciados, principalmente na Comunidade Econômica Europeia. Ding et al. ${ }^{1}$ analisaram os sistemas de estabelecimento de LEO em oito organizações asiáticas e dezessete europeias, em relação a semelhanças e diferenças segundo: a) critérios para determinar limites de exposição ocupacional; b) a seleção de compostos e; c) as concentrações dos limites de exposição ocupacional. De acordo com esse estudo, a maioria das organizações investigadas foi influenciada pela ACGIH para a definição de valores de LEO. O referido autor concluiu que o processo de harmonização dos LEOs tem demonstrado uma tendência de convergência interna na União Europeia; no entanto, as comparações entre organizações asiáticas e europeias não demonstraram evidências de esforços pela harmonização global e não tratam diferentemente os agentes carcinogênicos.

Em vários países, a maioria destes limites foi originalmente adotada na década de 1970, a partir dos valores-limite estabelecidos pela ACGIH, tal como ocorreu no Brasil ${ }^{8}$ com o estabelecimento da Lei $\mathrm{n}^{\circ}$ 3.214, de 08 de junho de 1978, e sua NR 15. Em alguns casos, como na Holanda, no final dos anos 1980, a crítica sobre as considerações não-científicas usadas para definir os LEOs sugeriu que esses limites poderiam não oferecer proteção suficiente para os trabalhadores, e essa situação fez o Ministério dos Assuntos Sociais e do Emprego holandês (Dutch Ministry of Social Affairs and Employment) solicitar ao Conselho de Saúde da Holanda (Health Council of the Netherlands) uma reavaliação dos LEOs que estavam contidos na lista holandesa ${ }^{52}$.

A Alemanha foi o primeiro país a introduzir o conceito de LEO, em 1886, e é um dos países que mais tem avançado nos critérios para o estabelecimento desses limites que, apesar de muitas falhas e críticas, continuam a ser um instrumento importante e válido para a proteção da saúde dos trabalhadores no contexto atual. A consideração teórica para a existência de limiares toxicológicos tem sido um referencial nesse país, e os pré-requisitos considerados para os LEOs são: a reversibilidade do efeito; a existência de um limiar; o desvio das funções fisiológicas do normal a ser considerado como "seguro"; e o conhecimento sobre os mecanismos tóxicos. Além disso, os compostos carcinogênicos, como é o caso do benzeno, constituem um caso especial por causa da não identificação de um limiar, e o estabelecimento de padrões baseados na saúde ainda não foi comprovadamente demonstrado ${ }^{53}$. Ainda na Alemanha, a Comissão de Investigação de Riscos de Compostos Químicos para a Saúde Ocupacional (Commission for the Investigation of Health Hazards of Chemical Compounds in the Work Area - MAK Commission) define os LEOs para componentes individuais e não para misturas. Para misturas que contenham compostos com um potencial genotóxico e carcinogênico, a Comissão considerou inadequado, cientificamente, estabelecer um limite seguro ${ }^{54}$. No entanto, em 2005, esse conceito foi revisto pelo Seguro Estatal Alemão de Acidentes de Trabalho e Doenças Profissionais (Deutsche Gesetzliche Unfallversicherung - DGUV) ${ }^{55}$ e, através de grupos de trabalho do Comitê para Substâncias Perigosas do Ministério Federal Alemão do Trabalho e Assuntos Sociais ${ }^{56}$, foi definida uma nova abordagem para a formulação de valores-limite para compostos carcinogênicos e genotóxicos, a qual prevê LEO baseado nos valores de risco de câncer de experiências com animais e/ou a partir de dados epidemiológicos. Essa abordagem busca a redução de valores-limite no ar com base no risco "aceitável" e "tolerável" de câncer no local de trabalho, cujos níveis foram acordados por representantes das partes interessadas em 4:100.000 e 4:1.000, respectivamente. Essa medida tem mostrado que as concentrações-limite de exposição ocupacional baseadas nos riscos de câncer podem estar bem abaixo dos antigos valores de concentração de exposição técnicos. Nesse contexto, a implementação do novo limite deve ser compreendida como uma necessidade de proteção melhorada e, se necessário, também sujeita a disposições transitórias e especiais até atingir esses valores.

Considerando os limites adotados por vários países para exposição ao benzeno, as variações são poucas. Geralmente, o LEO considera uma exposição durante 8 horas por dia, para uma semana de trabalho de 40 horas, e corresponde à média ponderada no tempo da exposição. Diferentes limites são preconizados por agências governamentais e não governamentais dos diversos países, denominados de distintas maneiras como TLV (Threshold Limit Values - ACGIH/EUA), PEL (Permissible Exposure Limits - OSHA/EUA), OELV (Occupational Exposure Limits Value - SCOEL (Scientific Committee on Occupational Exposure Limits)/União Europeia) e WEL (Workplace Exposure Limits - HSE (Health and Safety Executive)/Reino Unido). O TLV-STEL (Short-Term Exposure Limit) indica o limite de concentração para exposições por um curto período de tempo, e o TLV-TWA (Time Weighted Average) está baseado na média ponderada no tempo, não podendo ser ultrapassados na jornada de trabalho. No Brasil, foi adotado o Valor de Referência Tecnológico (VRT), no lugar de um limite de tolerância biológica, 
assumindo legalmente que, mesmo estabelecendo um limite de benzeno no ar em termos de vigilância sanitária, não se excluiu o risco à saúde ${ }^{8}$. Essa abordagem foi assumida no Brasil, a exemplo da experiência alemã, à época em que foi firmado o acordo do benzeno, e que atualmente passou a assumir uma nova estratégia de $\mathrm{LEO}^{57}$.

Nos Estados Unidos, valores-limite recomendados cada vez mais rigorosos foram sendo estabelecidos à medida que foram sendo evidenciados os efeitos tóxicos do benzeno, em especial sua associação com o efeito carcinogênico. Em meados de 1946, a ACGIH recomendou um TLV baseado na média ponderada no tempo (TLV-TWA) de 100 ppm. Dois anos mais tarde, o TLV foi reduzido à metade. Nos anos seguintes (1949 a 1976), ocorreram reduções adicionais, sendo o TLV mantido em 25 ppm até o ano de 1987, quando foi, então, drasticamente reduzido para 1 ppm. Já em 1997, o TLV foi fixado em 0,5 ppm ${ }^{29,58,59}$. Nesse país, os limites de exposição estabelecidos por lei pela Occupational Safety and Health Administration $(\mathrm{OSHA})^{60}$ foram de $10 \mathrm{ppm}$ em 1974, que foram alterados para $1 \mathrm{ppm}$ em 1987, sendo permitida uma exposição a $5 \mathrm{ppm}$ para exposição a curto prazo ${ }^{61}$. A adoção de limites de exposição para o benzeno por parte dos EUA repercutiu mundialmente e abriu espaço para que outros países também o fizessem. A agência federal dos EUA responsável pela realização de pesquisas e produção de recomendações para a prevenção de lesões e doenças relacionadas ao trabalho, o National Institute for Occupational Safety and Health (NIOSH), recomenda um valor-limite de exposição ao benzeno de 0,1 ppm para TWA de $10 \mathrm{~h}^{62}$.

Na Alemanha, a concentração máxima de benzeno no ambiente de trabalho, em 1974, era de $8 \mathrm{ppm}$. Anos mais tarde, esse valor também foi reduzido, sendo adotados valores de referência tecnológicos com níveis de $1,0 \mathrm{ppm}\left(3,25 \mathrm{mg} / \mathrm{m}^{3}\right)$ e $2,5 \mathrm{ppm}$ $\left(8,1 \mathrm{mg} / \mathrm{m}^{3}\right)$, dependendo da tecnologia da fonte emissora $^{63,64}$. Desde 2012, a Alemanha vem adotando valores-limite baseados em risco à saúde, estabelecidos pela Comissão para Substâncias Perigosas, do Ministério do Trabalho e Seguridade Social (Committee on Hazardous Substances - AGS) ${ }^{65}$. Para os riscos de trabalhadores expostos desenvolverem câncer relacionado ao benzeno, foram estabelecidos os seguintes valores de concentração ambiental: 0,6 ppm $\left(1,95 \mathrm{mg} / \mathrm{m}^{3}\right)$ para o risco tolerável de 4 casos para 1.000 expostos; 0,06 ppm $\left(0,2 \mathrm{mg} / \mathrm{m}^{3}\right)$ para o risco aceitável de 4 casos para 10.000 expostos até 2013; e 0,006 ppm $\left(0,02 \mathrm{mg} / \mathrm{m}^{3}\right)$ até 2018 , quando o risco aceitável passa a ser de 4 casos para 100.000 expostos.

Coréia do Sul ${ }^{66}$, Singapura ${ }^{67}$, Japão ${ }^{68}$ e Europa $^{69,70}$ estabeleceram medidas no intuito de regular a exposição ocupacional ao benzeno com LEO de 1 ppm para uma TWA. Já na Austrália, a National Occupational Health and Safety Commission (NOHSC) admite TWA até 5 ppm $^{29,61,64}$. No caso de Hong-Kong ${ }^{71}$, o valor-limite da TWA-8h recomendado é de 0,5 ppm. Em Taiwan, o valor-limite de exposição de TWA-8h é de 5 ppm até o momento; mas, com base em novos estudos, pode vir a ser reduzido para $0,5 \mathrm{ppm}^{38}$.

Por outro lado, na Holanda, o Comitê de Especialistas em Segurança do Trabalho (Dutch Expert Committee on Occupational Safety - DECOS) recomenda um LEO para o benzeno da TWA-8h de $0,7 \mathrm{mg} / \mathrm{m}^{3}(0,2 \mathrm{ppm})$. Cabe destacar que o DECOS revisou vários estudos epidemiológicos e toxicológicos e derivou o LEO a partir dos valores relatados de NOAEL (nível de efeito adverso não observado) e LOAEL (nível do menor efeito observado) e aplicado a estes um fator de incerteza de 3 , tendo em vista o agregado de evidências ${ }^{72}$.

Na China, ações referentes à limitação da exposição ao benzeno iniciaram-se posteriormente em virtude do processo de industrialização tardio ocorrido no país. Nesse sentido, enquanto EUA e países da Europa esforçavam-se para reduzir ao máximo a exposição de trabalhadores, na China multiplicavam-se os casos de intoxicação por benzeno em virtude da rápida industrialização desvinculada de medidas preventivas e de proteção à saúde destes trabalhadores. No entanto, a partir da década de 1980, quando diversos trabalhos foram publicados sobre os riscos associados à exposição ao benzeno na China, estes alcançaram repercussão internacional. Na China, o Comitê Nacional Tecnológico de Padrões de Saúde e Ambiente da China (National Technological Committee of Health Standards Setting - NTCHSS) preconiza, desde 2002, uma média ponderada pelo tempo de 2 ppm (TWA), com limite de exposição de até 3 ppm, durante 15 minutos (STEL) ${ }^{61}$.

No Brasil, a literatura científica registra publicações alertando para o risco da exposição ocupacional ao benzeno desde os anos 1940. No entanto, os esforços para controlar a exposição ocupacional só se iniciaram em 1982, quando o benzeno já havia sido reconhecido como carcinógeno humano pela IARC. No entanto, as medidas legais tornaram-se coerentes somente a partir de 1995, com o anexo 13-A acrescentado pela Portaria $\mathrm{n}^{\mathrm{o}} 14$, de 20 de dezembro de 1995, à NR 15, que estabeleceu o Valor de Referência Tecnológico (VRT) para o benzeno. A abordagem do VRT pressupõe que esforços devem ser despendidos continuamente no sentido de buscar uma tecnologia mais adequada para minimizar a exposição do trabalhador ao benzeno. Os valores do VRT são 1,0 ppm para as empresas que produzem, transportam, armazenam, utilizam ou manipulam benzeno e suas misturas líquidas; e 2,5 ppm para as siderúrgicas (anexo 13-A da NR 15) ${ }^{8}$. 
Alguns países ou organizações não apresentam valores-limite, mas definem o nível de risco para leucemia dependendo da exposição, como a Agência de Proteção Ambiental dos Estados Unidos $(\mathrm{EPA})^{73}$ e a Organização Mundial da Saúde (OMS) ${ }^{74}$, dentre outras ${ }^{75-79}$. É também o caso do Japão, que emprega um valor-limite TWA-8h de $1 \mathrm{ppm}$ na sua legislação, mas também faz recomendações avaliando um risco para leucemia de $10^{-3}$ com uma exposição de $1 \mathrm{ppm}$, e um risco para leucemia de $10^{-4}$ com uma exposição de $0,1 \mathrm{ppm}$, mostrando bem que o valor-limite legal não exclui o risco para a saúde ${ }^{68}$. A Tabela 2 apresenta os Limites de Exposição Ocupacional (LEO) adotados ou recomendados para o benzeno em vários países, bem como as referências de órgãos internacionais para o risco de leucemia.

Tabela 2 Limite de Exposição Ocupacional (LEO) e recomendações para benzeno em vários países e órgãos internacionais

\begin{tabular}{|c|c|c|}
\hline País & LEO / recomendação & Referência \\
\hline Brasil & $\begin{array}{l}1 \text { ppm (VRT 8h) Petroquímicas } \\
\text { 2,5 ppm (VRT 8h) Siderúrgicas }\end{array}$ & MTE, $1995^{2}$ \\
\hline China & $\begin{array}{l}2 \mathrm{ppm}(\mathrm{TWA} 8 \mathrm{~h}) \\
3 \mathrm{ppm}(\mathrm{STEL})\end{array}$ & Weisel, $2010^{61}$ \\
\hline Coréia do Sul & 1 ppm (TWA 8h) & Park et al., $2011^{75}$ \\
\hline $\begin{array}{l}\text { EUA } \\
\text { ACGIH }\end{array}$ & $\begin{array}{l}0,5 \mathrm{ppm} \text { (TWA 8h) } \\
2,5 \mathrm{ppm} \text { (STEL) }\end{array}$ & ACGIH, $2016^{76}$ \\
\hline $\mathrm{NIOSH}$ & $\begin{array}{l}0,1 \mathrm{ppm} \text { (TWA 10h) } \\
1 \mathrm{ppm}(\mathrm{STEL})\end{array}$ & $\mathrm{NIOSH}, 2007^{62}$ \\
\hline OSHA & $\begin{array}{l}1 \text { ppm (TWA 8h) } \\
5 \text { ppm (STEL) }\end{array}$ & OSHA, $2014^{60}$ \\
\hline $\mathrm{EPA}$ & Risco para leucemia a 1 ppm de exposição de $7,1 \times 10^{3}$ a $2,5 \times 10^{-2}$ & $\mathrm{EPA}, 1998^{73}$ \\
\hline $\begin{array}{l}\text { França } \\
\text { INRS }\end{array}$ & 1 ppm (TWA 8h) & Bonnard et al., $2007^{69}$ \\
\hline ANSES & $\begin{array}{l}0,038 \mu \mathrm{g} \cdot \mathrm{m}^{-3}-\text { risco de } 10^{-6} \text { (risco de leucemia aguda) } \\
0,38 \mu \mathrm{g} \cdot \mathrm{m}^{-3} \text { - risco de } 10^{-5} \text { (risco de leucemia aguda) } \\
3,8 \mu \mathrm{g} \cdot \mathrm{m}^{-3} \text { - risco de } 10^{-4} \text { (risco de leucemia aguda) }\end{array}$ & ANSES, $2014^{77}$ \\
\hline Holanda & 0,2 ppm (TWA 8h) & $\begin{array}{l}\text { Health Council of the Netherlands, } \\
2014^{72}\end{array}$ \\
\hline Hong-Kong & $\begin{array}{l}0,5 \text { ppm (TWA 8h) } \\
2,5 \text { ppm (STEL) }\end{array}$ & Tsin, $2006^{71}$ \\
\hline Itália & $3200 \mu \mathrm{g} / \mathrm{m}^{3}$ (1 ppm) ambiente de trabalho & Scapellato et al., $2013^{78}$ \\
\hline Japão & $\begin{array}{l}0,1 \mathrm{ppm} \text { para risco de câncer de } 1 \times 10^{-4} \\
1 \mathrm{ppm} \text { para risco de câncer de } 1 \times 10^{-3}\end{array}$ & $\begin{array}{l}\text { Takahashi e Higashi, } 2006^{68} \text {; } \\
\text { Arito, } 2015^{79}\end{array}$ \\
\hline Singapura & 1 ppm (TWA 8h) & Tang et al., $2006^{67}$ \\
\hline Taiwan & $\begin{array}{l}5 \text { ppm (TWA 8h) } \\
10 \text { ppm (STEL) }\end{array}$ & Shih et al., $2006^{38}$ \\
\hline União Europeia & 1 ppm (TWA) & Arnold et al., $2013^{29}$ \\
\hline WHO & $\begin{array}{l}17 \mu \mathrm{g} / \mathrm{m}^{3}(5,27 \mathrm{ppb}) \text { para risco de leucemia de } 1 / 10.000 \\
1,7 \mu \mathrm{g} / \mathrm{m}^{3}(0,527 \mathrm{ppb}) \text { para risco de leucemia de } 1 / 100.000 \\
0,17 \mu \mathrm{g} / \mathrm{m}^{3}(0,053 \mathrm{ppb}) \text { para risco de leucemia de } 1 / 1.000 .000\end{array}$ & WHO, $2010^{74}$ \\
\hline
\end{tabular}

VRT = Valor de Referência Tecnológico; TWA = Time Weighted Average; STEL = Short-Term Exposure Limit; 1ppm (3,25 mg/m³). 


\section{Visão crítica sobre os limites de exposição ao benzeno frente às evidências toxicológicas}

O cenário mundial quanto aos limites de exposição ao benzeno é marcado por uma heterogeneidade de abordagens e de valores adotados. De modo geral, a escolha de valores-limite para cada país ou região sofre a influência dos valores recomendados por organizações americanas e, muitas vezes, este valor corresponde mais a um número atingível do ponto de vista tecnológico do que tendo como base as evidências toxicológicas para a segurança e saúde dos trabalhadores ${ }^{80}$.

Esses valores são frequentemente apresentados como seguros, o que se contrapõe frontalmente com os valores já existentes de risco para leucemia ${ }^{68}$. Assim, essa discussão tornou-se ideologizada principalmente por parte das empresas, fortalecidas pelos textos regulatórios que vinculam a inexistência de risco à adequação a parâmetros da regulação. Entretanto, cabe questionar se tais limites são efetivamente seguros para a saúde humana, uma vez que relatos científicos sobre efeitos tóxicos do benzeno multiplicam-se, mostrando que efeitos adversos ocorrem mesmo com exposições menores do que os valores-limite.

Atualmente, predominam as exposições a baixas concentrações de benzeno e estas se tornaram objeto de diversas investigações realizadas nas últimas duas décadas, especialmente após a publicação de estudos que demonstraram que o metabolismo dose-específico do benzeno está mais ativo em concentrações inferiores a 1 ppm deste hidrocarboneto ${ }^{4,81,82}$. A relevância de tais estudos é facilmente compreendida pelo fato de que os efeitos tóxicos produzidos por esse composto químico são mediados por seus produtos de biotransformação associados à mielotoxicidade com alterações na formação de células sanguíneas e leucemogênese ${ }^{27}$.

Os estudos voltados à avaliação da exposição a compostos químicos e o risco de câncer têm se dedicado a identificar os produtos carcinogênicos e outros não carcinogênicos de forma isolada. No entanto, a exposição crônica ao longo da vida se dá por misturas de agentes químicos, sejam carcinogênicos ou não, e a presença desses compostos no ambiente, sendo que para algumas dessas substâncias, como o benzeno, a exposição é ubíqua. Recentemente, pesquisadores de diferentes países, dos campos da saúde ambiental e do câncer, sistematizaram o resultado de discussões relacionadas à exposição a baixas doses de misturas de compostos químicos, entre eles o benzeno, e mecanismos da carcinogênese ${ }^{83}$. Os autores concluíram que a abordagem empregada pela OMS, em seu Programa Internacional Relacionado à Segurança
Química (World Health Organization International Programme on Chemical Safety) baseada no "Modo de Ação" (Mode of Action, MoA), que considera eventos-chave para o aparecimento de câncer quando o mecanismo de ação do composto no organismo não é ainda conhecido, deve ser revista, pois apresenta fragilidades que não estão totalmente alinhadas com a atual compreensão da biologia do câncer ${ }^{84}$.

Exemplo disso são estudos como o de Vermeulen et al. ${ }^{36}$, em que os pesquisadores compararam 250 trabalhadores de fábricas de sapato expostos ao benzeno com 140 não expostos, na cidade de Tianjin, na China. Os resultados mostraram uma redução significativa na contagem de leucócitos e plaquetas em sangue periférico de indivíduos expostos ao benzeno em concentrações inferiores a $1 \mathrm{ppm}$. Foi observado também um decréscimo acentuado e dose-dependente no número de células progenitoras. Entretanto, cabe ressaltar que na mesma população chinesa foram identificadas alterações genéticas, levando a uma diminuição da capacidade de biotransformar os metabólitos ativos do benzeno, o que torna os indivíduos mais susceptíveis à toxicidade do benzeno ${ }^{82,85}$.

Outra investigação, conduzida por Marchetti et al..$^{59}$, avaliou indivíduos do sexo masculino que trabalhavam em fábricas que utilizavam benzeno em seus processos produtivos em Tianjin, China. Os resultados mostraram uma associação positiva entre a ocorrência de espermatozoides com aberrações cromossômicas no líquido seminal de indivíduos expostos a concentrações de benzeno no ar menores que 1 ppm. Os autores sugerem que o benzeno seja capaz de promover dano cromossômico mesmo em baixas doses de exposição. Observações semelhantes foram feitas em 2010, em outro estudo com trabalhadores expostos também em fábricas chinesas, onde foi constatada associação entre aneuploidias dos cromossomos X, Y e 21 em esperma de indivíduos expostos a concentrações em torno de $1 \mathrm{ppm}^{86}$. Ji et al. ${ }^{87}$ observaram associação entre a exposição ao solvente e aneuploidias de linfócitos de sangue periférico e esperma em trabalhadores chineses, observando trissomia do cromossomo 21 em linfócitos e alterações de cromossomos sexuais em espermatozoides. Cabe ressaltar que os efeitos tóxicos observados nesses estudos ocorreram em concentrações de benzeno no ar menores que os limites de exposição estabelecidos pelo NTCHSS (2 ppm).

Na Itália, Angelini et al. ${ }^{88}$ observaram maior frequência na formação de micronúcleos em 70 policiais de trânsito expostos a concentrações de benzeno entre 0,0009 ppm e 0,006 ppm, seis vezes superiores à concentração de exposição dos 40 controles do estudo. O estudo sugere um aumento dos riscos à saúde decorrente da emissão de benzeno no tráfego. Basso et al. ${ }^{89}$ avaliaram os efeitos da exposição a compostos tóxicos, incluindo o benzeno, em 
79 trabalhadores de duas refinarias de petróleo italianas em comparação com 50 controles; os resultados encontrados mostraram um aumento significativo da formação de micronúcleos em linfócitos de sangue periférico no grupo de trabalhadores expostos.

Diante desses estudos e discussões, fica evidente a complexidade em torno da exposição ao benzeno e seus efeitos, seja pela variedade de fontes do benzeno, pela ampla faixa de concentrações nas quais este composto é encontrado, assim como pela possibilidade da associação com polimorfismos genéticos em populações expostas, que pode levar a uma maior suscetibilidade aos efeitos mielotóxicos. De frentistas de postos de combustíveis a trabalhadores de fábrica de calçados, é possível observar concentrações de benzeno no ar inferiores às concentrações observadas em populações ambientalmente expostas, bem como concentrações mil vezes superiores aos valores ambientais. Estudos de monitoramento de benzeno no ar têm permitido avaliar o impacto provocado pelas emissões de veículos automotores, indicando que estes constituem a principal fonte de exposição ambiental de benzeno em áreas urbanas. Em estudo mais recente realizado na China ${ }^{90}$, a concentração de benzeno no ar em área urbana de Beijing variou de 0,99 a $49,71 \mu \mathrm{g} / \mathrm{m}^{3}$; com média de $11,98 \mu \mathrm{g} / \mathrm{m}^{3}$.

Para fins de compreensão dos efeitos, empregando as estimativas de risco encontradas na literatura, Takahashi e Higashi ${ }^{68}$ estimaram que, para um quadro de exposição de até 10 ppb na população geral, corresponderia um risco para leucemia de $10^{-5}$, enquanto que para exposição a $30 \mathrm{ppb}$, o risco seria de $3 \times 10^{-5}$ e, num quadro mais grave de exposição ocupacional a $40 \mathrm{ppm}$, o risco de desenvolvimento de leucemia seria de $4 \times 10^{-2}$. Considerando esses três níveis de gradientes de exposição, os autores apresentaram as correspondências de risco de leucemias.

\section{Considerações finais}

Ao avaliar o marco normativo brasileiro e suas diretrizes orientadoras para as empresas que empregam benzeno em seus processos produtivos, o que se percebe é que essas normas/legislações não conseguiram proteger os trabalhadores dos efeitos da toxicidade do benzeno ao longo do período analisado, pois as mudanças pela redução das concentrações ambientais só ocorreram muito tempo após as comprovações de danos à saúde dos trabalhadores, o que resultou em sequencias de reduções dos limiares de exposição. E, atualmente, novas evidências científicas de alterações hematológicas devido à exposição a baixas concentrações de benzeno ainda não foram plenamente incorporadas às normas internacionais e nacional.
De fato, a toxicidade relacionada ao benzeno ainda não está completamente desvendada. Ainda há muito a ser investigado; dessa forma, o estabelecimento de um limite seguro de exposição a esse composto depende essencialmente da sua caracterização, uma vez que as evidências científicas recentes apontam para a não existência deste limite para agentes carcinogênicos, como é o caso do benzeno. Para essa caracterização, devem ser incluídos todos os setores de produção onde há a exposição ao benzeno, seja na sua forma pura ou presente na gasolina.

Além disso, o cenário regulatório da exposição ao benzeno é marcado por relações de contrapoder ${ }^{91,92}$, construído pelo movimento social/político, histórico e técnico, que é mediado por interesses político-econômicos e concepções e interesses diversos, evidências científicas, metodologias singulares, disciplinas distintas e inovações tecnológicas. A fundamentação normatizada tende a valorizar métodos e resultados quantitativos em que predominam as medidas de exposição como forma de avaliação de risco. No entanto, as medidas são sempre expressões médias ou pontuais e não conseguem reproduzir as situações reais da contínua exposição a que estão submetidos os trabalhadores. Representam, no entanto, parâmetros de acompanhamento, como tais, e consistem em ferramentas úteis para o desenvolvimento de ações de vigilância em saúde ambiental e do trabalhador.

Ao revisar as normas brasileiras, em relação à adoção de padrão nacional de concentração de benzeno no ambiente, evidencia-se a ausência de valor de referência para ambientes urbanos e o VRT, que foi definido para ambientes ocupacionais, até o momento não se aplica às atividades dos PRCs, pois se encontra em debate na CNPBz.

No contexto das discussões normativas, uma das características deste campo é o alto grau de assepsia coorporativa, em que os interesses das empresas se encontram ocultados pelo cenário turvo das práticas de gestão artificial de risco, em que acidentes, vazamentos, emissões fugitivas, situações de risco que não têm visibilidade, fazem parte do cotidiano dos trabalhadores, em especial aqueles de setores químicos, do petróleo e siderúrgico no Brasil, os quais têm dificuldades de ver concretizadas suas reivindicações de melhoria das condições de trabalho. Os cenários da exposição são trazidos dessa forma para o campo da tomada de decisão do que fazer em relação à normatização e à redução de riscos. Nesse contexto, a discussão dos PRCs se insere no âmbito da CNPBz que, por sua vez, perpetua esse processo marcado pela influência da gestão industrial do controle do benzeno no Brasil.

Esta revisão identificou lacunas do marco legal vigente, em relação à proteção dos trabalhadores 
de PRCs; em contrapartida, também identificou interesses que pressionam o processo regulatório. Portanto, sugere-se um aperfeiçoamento periódico desse marco legal, para a minimização da exposição ao benzeno em trabalhadores dos PRCs, assim como da população do entorno destes estabelecimentos. É importante o uso de tecnologias capazes de reduzir as emissões de benzeno no ar, em ambientes de trabalho e no meio ambiente em geral, além do desenvolvimento de estudos nacionais, para estimar os níveis de exposição e identificar metodologias apropriadas para o monitoramento dessa exposição. Imprescindível, também, a inserção desses trabalhadores em treinamentos periódicos, com acesso à informação sobre exposição ao benzeno, para assegurar que as atividades de trabalho sejam executadas conforme as melhores práticas sanitárias e permitindo que os próprios trabalhadores organizem-se para exigir o cumprimento, por parte dos empregadores, da realização dos exames periódicos e a implementação das condições mínimas de trabalho que as normas reguladoras brasileiras preconizam, hoje ainda não cumpridas em grande parte dos postos de combustíveis no Brasil.

\section{Contribuições de autoria}

Todos os autores contribuíram substancialmente no projeto e delineamento do trabalho, no levantamento de dados, na sua análise e interpretação.

\section{Agradecimentos}

Os autores agradecem ao pesquisador Danilo Fernandes Costa do Ministério do Trabalho de São Paulo (MTSP)/Superintendência Regional do Trabalho e Emprego de SP/ Seção de Segurança e Saúde do Trabalhador (Segur), pelas correções, sugestões e avaliação crítica deste trabalho.

\section{Referências}

1. Ding Q, Schenk L, Malkiewicz K, Hansson SO. Occupational exposure limits in Europe and Asia: continued divergence or global harmonization? Regul Toxicol Pharmacol. 2011;61(3):296-309.

2. Ministério do Trabalho e Emprego (Brasil). Acordo e legislação sobre o benzeno. São Paulo: Fundacentro; 1995.

3. Ministério do Trabalho e Emprego (Brasil). Portaria SIT n ${ }^{\circ} 252$, de 4 de agosto de 2011. Constitui a Subcomissão de Postos de Revendedores de Combustíveis. Diário Oficial da União 4 ago 2011;Seção 1.

4. Rappaport SM, Kim S, Lan Q, Vermeulen R, Waidyanatha S, Zhang L, et al. Evidence that humans metabolize benzene via two pathways. Environ Health Perspect. 2009;117(6):946-52.

5. Koh DH, Jeon HK, Lee SG, Ryu HW. The relationship between low-level benzene exposure and blood cell counts in Korean workers. Occup Environ Med. 2015; 72(6):421-7.

6. Ruiz MA, Lorand-Metze I, Augusto LGS, Souza CA. Characteristics of the hemopoietic abnormalities after chronic exposure to benzene. Leuk Res. 1994;18(Suppl):29.

7. Ruiz MA, Vassallo J, Souza CA. Alterações hematológicas em pacientes expostos cronicamente ao benzeno. Rev Saúde Pública. 1993;27(2):145-51.
8. Ministério do Trabalho e Emprego (Brasil). Portaria SIT $n^{\circ} 291$, de 8 de dezembro de 2011. Altera o anexo 13-A (Benzeno) da NR 15 (Atividades e Operações Insalubres); Portaria SIT n ${ }^{\circ} 207$, de 11 de março de 2011. Relativas à Segurança e Medicina do Trabalho. Diário Oficial da União 11 mar 2011;Seção 1.

9. Ministério do Trabalho e Emprego (Brasil). Nota Técnica COREG n ${ }^{\circ}$ 07, 12 de setembro de 2002. Propõem abrangência do campo de aplicação do acordo e legislação do benzeno e do anexo 13 da NR 15. Diário Oficial da União 12 set 2002.

10. Ministério do Trabalho e Emprego (Brasil). Portaria SIT $n^{\circ} 308$, de 29 de fevereiro de 2012. Dispõe a Secretaria de Inspeção do Trabalho - SIT, NR 20 Segurança e Saúde no Trabalho com Inflamáveis e Combustíveis. Diário Oficial da União 6 mar 2012.

11. Ministério do Trabalho e Previdência Social (Brasil). Portaria MTPS n ${ }^{0}$ 1109, de 21 de setembro de 2016. Aprova o Anexo 2, Exposição Ocupacional ao Benzeno em Postos Revendedores de Combustíveis (PRC), da Norma Regulamentadora $n^{\circ}$ 9, Programa de Prevenção de Riscos Ambientais (PPRA). Diário Oficial da União 22 set 2016.

12. Fustinoni S, Campo L, Satta G, Campagna M, Ibba A, Tocco MG, et al. Environmental and lifestyle factors affect benzene uptake biomonitoring of residents near a petrochemical plant. Environ Int. 2012;39(1):2-7. 
13. World Health Organization. Environmental Health Criteria 155. Biomarkers and risk assessment: concepts and principles. International Programme on Chemical Safety (IPCS). Ann Occup Hyg. 1994;38(6):969-71.

14. Agência Nacional do Petróleo (Brasil). Resolução ANP $n^{\circ} 40$, de 25 de outubro de 2013. Estabelece as especificações para a comercialização de gasolinas automotivas em todo o território nacional e obrigações dos agentes econômicos. Diário Oficial da União 28 out 2011.

15. Brasil. Decreto no 6.514, de 22 de julho de 2008. Dispõe sobre as infrações e sanções administrativas ao meio ambiente. Diário Oficial da União 22 abr 2008;Seção 1.

16. Ministério do Trabalho e Emprego (Brasil). Portaria $\mathrm{n}^{\circ}$ 01, de 18 de março de 1996. Instala a Comissão Nacional Permanente do Benzeno (CNPBz) nas dependências do Centro Técnico Nacional da Fundacentro/SP. Diário Oficial da União 20 mar 1996;Seção 2:15.

17. Conselho Nacional do Meio Ambiente (Brasil). Resolução n ${ }^{\circ} 273$, de 29 de novembro de 2000. Dispõe sobre prevenção e controle da poluição em postos de combustíveis e serviços. Diário Oficial da União 8 jan 2001;Seção 1:20-3.

18. Conselho Nacional do Meio Ambiente (Brasil). Resolução n ${ }^{\circ} 319$, de 4 de dezembro de 2002. Dispõe sobre a prevenção e controle da poluição em postos de combustíveis e serviços. Diário Oficial da União 19 dez 2002;Seção 1:224-5.

19. Associação Brasileira de Normas Técnicas (Brasil). NBR 13.786. Dispõe sobre Armazenamento de líquidos inflamáveis e combustíveis - Seleção dos componentes para instalação de sistema de armazenamento subterrâneo de combustíveis (SASC). Brasília: ABNT; 2014.

20. Moraes G. Normas Regulamentadoras Comentadas e Ilustradas. 8. ed., Rio de Janeiro: GVC; 2013. p. 344. (Caderno Complementar, v. 4).

21. Agencia Nacional do Petróleo (Brasil). Resolução $\mathrm{n}^{\mathrm{o}} 41$, de 5 de novembro de 2013. Estabelece requisitos para autorização de exercício da atividade de revenda varejista de combustíveis automotivos. Diário Oficial da União 6 nov 2013;Seção 1:71-4.

22. International Agency for Research on Cancer. IARC. Chemical agents and related occupations. Monographs on the Evaluation of Carcinogenic Risks to Humans. Lyon, France: World Health Organization, 2012. p. 249-94.[Cited 2017 jun. 9]. Available from: http://monographs.iarc.fr/ENG/ Monographs/vol100F/mono100F.pdf

23. Schenk L, Johanson G. Use of uncertainty factors by the SCOEL in their derivation of health-based occupational exposure limits. Crit Rev Toxicol. 2010;40(9):791-8.

24. Ministério da Saúde (Brasil). Portaria SAS n 776 , de 28 de abril de 2004. Dispõe sobre a regulamentação dos procedimentos relativos à vigilância da saúde dos trabalhadores expostos ao benzeno. Diário Oficial da União 28 abr 2004;Seção 1.
25. Agency for Toxic Substances and Disease Registry. Toxicological profile for Benzene (Update). Atlanta, GA: U.S. Department of Health and Human Services; 2007.

26. Ross D, Zhou HF. Relationships between metabolic and non-metabolic susceptibility factors in benzene toxicity. Chem Biol Interact. 2010;184(1-2):222-8.

27. Smith MT. Advances in understanding benzene health effects and susceptibility. Annu Rev Public Health. 2010;31:133-48.

28. Tunsaringkarn T, Siriwong W, Rungsiyothin A, Nopparatbundit S. Occupational exposure of gasoline station workers to BTEX compounds in Bangkok, Thailand. Int J Occup Environ Med. 2012;3(3):117-25.

29. Arnold SM, Angerer J, Boogaard PJ, Hughes MF, O'Lone RB, Robison SH, et al. The use of biomonitoring data in exposure and human health risk assessment: benzene case study. Crit Rev Toxicol. 2013;43(2):119-53.

30. Augusto LGS, Vigoritto AC, Souza CA. Alterações histológicas de medula óssea secundária à exposição ao benzeno e a evolução hematológica do sangue periférico em pacientes acometidos. Rev Bras Saúde Ocup. 1993;21:85-92.

31. Khalade A, Jaakkola MS, Pukkala E, Jaakkola JJK. Exposure to benzene at work and the risk of leukemia: a systematic review and meta-analysis. Environ Health. 2010;9:31.

32. Glass DC, Schnatter AR, Tang G, Irons RD, Rushton L. Risk of myeloproliferative disease and chronic myeloid leukaemia following exposure to low-level benzene in a nested case-control study of petroleum workers. Occup Environ Med. 2014;71(4):266-74.

33. Schnatter AR, Glass DC, Tang G, Irons RD, Rushton L. Myelodysplastic syndrome and benzene exposure among petroleum workers: an international pooled analysis. J Natl Cancer Inst. 2012;104(22):1724-37.

34. Wang L, Zhou Y, Liang Y, Wong O, Armstrong T, Schnatter AR, et al. Benzene exposure in the shoe making industry in China, a literature survey, 19782004. Regul Toxicol Pharmacol. 2006;46(2):149-56.

35. Qing L, Luoping Z, Guilan L, Roel V, Rona SW, Mustafa D, et al. Hematotoxicity in workers exposed to low levels of benzene. Science. 2004;306(5702):1774-6.

36. Vermeulen R, Li G, Lan Q, Dosemeci M, Rappaport SM, Bohong X, et al. Detailed exposure assessment for a molecular epidemiology study of benzene in two shoe factories in China. Ann Occup Hyg. 2004;48(2):105-16.

37. Liang Y, Wong O, Yang L, Li T, Su Z. The development and regulation of occupational exposure limits in China. Regul Toxicol Pharmacol. 2006;46(2):107-13.

38. Shih TS, Wu KY, Chen HI, Chang CP, Chang HY, Huang YS, et al. The development and regulation of occupational limits in Taiwan. Regul Toxicol Pharmacol. 2006;46(2):142-8. 
39. Mayan O, Pires A, Neves P, Capela F. Shoe manufacturing and solvent exposure in Northern Portugal. Appl Occup Environ Hyg. 1999;14(11):785-90.

40. Glass DC, Adams GG, Manuell RW, Bisby JA. Retrospective exposure assessment for benzene in the Australian petroleum industry. Annals of Occup Hyg. 2000;44(4):301-20.

41. Costa, MFB. Estudo da aplicabilidade do ácido trans, trans-Mucônico Urinário como indicador biológico de exposição ao Benzeno. Rio de Janeiro. Tese [Doutorado em Saúde Pública] - Escola Nacional de Saúde Pública Sérgio Arouca; 2001.

42. Rao PS, Ansari MF, Gavane AG, Pandit VI, Nema P, Devotta S. Seasonal variation of toxic benzene emissions in petroleum refinery. Environ Monit Assess. 2007;128(1-3):323-8.

43. Sorensen M, Poole J, Autrup H, Muzyka V, Jensen A, Loft S, et al. Benzene exposure assessed by metabolite excretion in Estonian oil shale mineworkers: influence of glutathione $S$-transferase polymorphisms. Cancer Epidemiol Biomarkers Prev. 2004;13(11 Pt 1):1729-35.

44. Hsu DJ, Huang HL, Chien CH, Lin TS. Potential exposure to VOCs caused by dry process photocopiers: results from a chamber study. Bull Environ Contam Toxicol. 2005;75(6):1150-5.

45. Hsu DJ, Huang HL, Lin HY, Lin TS. Potential volatile organic compound exposure from dry process photocopiers in operation-idle mode. Bull Environ Contam Toxicol. 2006 ;76(6):922-9.

46. Fedoruk MJ, Bronstein R, Kerger BD. Benzene exposure assessment for use of a mineral spiritsbased degreaser. Appl Occup Environ Hyg. 2003;18(10):764-71.

47. Lü H, Wen S, Feng Y, Wang X, Bi X, Sheng G, et al. Indoor and outdoor carbonyl compounds and BTEX in the hospitals of Guangzhou, China. Sci Total Environ. 2006;368(2-3):574-84.

48. Field RA, Ballesta PP, Caracena AB, Nikolova I, Connolly R, Cao N, et al. Population exposure to air pollutants in Europe (PEOPLE): Methodological strategy and basic results. Inst for Environ and Sustainab. 2005;1-74.

49. Schnatter AR, Kerzic PJ, Zhou Y, Chen M, Nicolich MJ, Lavelle K, et al. Peripheral blood effects in benzene-exposed workers. Chem Biol Interact. 2010;184(1-2):174-81.

50. Lagorio S, Fuselli S, Iavarone I, Vanacore N, Carere A. Exposure to benzene of service station employees and composition of benzene. Med Lav. 1994;85(5):412-21.

51. Nielsen GD, Ovrebø S. Background, approaches and recent trends for setting health-based occupational exposure limits: a minireview. Regul Toxicol Pharmacol. 2008;51(3):253-69.

52. Stouten H, Ott H, Bouwman C, Wardenbach P. Reassessment of occupational exposure limits. Am J Ind Med. 2008;51(6):407-18.
53. Henschler D. The concept of occupational exposure limits. Sci Total Environ. 1991;101(1-2):916.

54. Bartsch R, Forderkunz S, Reuter U, Sterzl-Eckert $\mathrm{H}$, Greim H. Maximum workplace concentration values and carcinogenicity classification for mixtures. Environ Health Perspect. 1998;106(Suppl 6):1291-3.

55. Degen GH, Nies E. Luftgrenzwerte für krebserzeugende Arbeitsstoffe - aus der Arbeit des AK CM im AGS. (Ausschuss für Gefahrstoffe - AGS). Gefahrstoffe Reinhalt Luft. 2008;68(7-8):299-302.

56. Bundesanstalt für Arbeitsschutz und Arbeitsmedizin (BAuA). Technische Regeln für Gefahrstoffe, Risikobezogenes Maßnahmenkonzept für Tätigkeiten mit krebserzeugenden Gefahrstoffen - TRGS 910. Ausgabe: Februar 2014. [Zugang in 2 apr. 2014]. Erhältlich in: https://www.baua.de/DE/Angebote/Rechtstexteund-Technische-Regeln/Regelwerk/TRGS/pdf/ TRGS-910.pdf?_blob $=$ publicationFile\&v $=6 \mathrm{i}$

57. Deutsche Gesetzliche Unfallversicherung . Occupational Disease $n^{0} 1317$. Polyneuropathy or encephalopathy caused by organic solvents, in isolation or in mixtures Berlin. Berlin: Occupational Disease Report; 2/2007e.

58. Galbraith D, Paustenbach D, Gross SA. Benzene and human health: a historical review and appraisal of associations with various diseases. Crit Rev Toxicol. 2010;40(Suppl 2):1-46.

59. Marchetti F, Eskenazi B, Weldon RH, Li G, Zhang L, Rappaport SM, et al. Occupational exposure to Benzene and chromosomal structural aberrations in the sperm of Chinese men. Environ Health Perspect. 2012;120(2):229-34.

60. Occupational Safety And Health Administration. Regulations (OSHA) (Standards - 29 CFR). Benzene. 2014;1910-1928. [Cited 2017 jun. 9]. Available from: https://www.osha.gov/pls/oshaweb/owadisp. show_document?p_id=10042\&p_table=standards

61. Weisel CP. Benzene exposure: an overview of monitoring methods and their findings. Chem Biol Interact. 2010;184(1-2):58-66.

62. National Institute For Occupational Safety And Health. NIOSH Pocket Guide to Chemical Hazards. United States: NIOSH; 2007. p. 26 (Benzene).

63. Pezzagno G. Monitoraggio biológico delle poppolazioni exposte a benzene. Em Minoia C, Apostoli P, Bartolucci GB (Eds.). II Benzene: tossicologia, ambienti di vita e di lavoro. Milano: Morgan Edizioni Tecniche; 1995. p. 125-45.

64. Coutrim MX, Carvalho LRF, Arcuri ASA. Avaliação dos métodos analíticos para a determinação de metabólitos do benzeno como potenciais biomarcadores de exposição humana ao benzeno no ar. Química Nova. 2000;23(5):653-63.

65. Committee on Hazardous Substances. Technical Rules For Hazardous Substances (TRGS). Germany: GMBI; 2016. p. 1-154. [Cited 2017 
jun. 9]. Available from: https://www.baua.de/DE/ Angebote/Rechtstexte-und-Technische-Regeln/ Regelwerk/TRGS/pdf/en/TRGS-910.pdf? blob $=$ publicationFile\&v $=3$

66. Paek D, Park DY. The development and regulation of occupational exposure limits in Korea. Regul Toxicol Pharmacol. 2006;46(2):126-30.

67. Tang TK, Siang LH, Koh D. The development and regulation of occupational exposure limits in Singapore. Regul Toxicol Pharmacol. 2006;46(2):136-41.

68. Takahashi K, Higashi T. The development and regulation of occupational exposure limits in Japan. Regul Toxicol Pharmacol. 2006;46(2):120-5.

69. Bonnard N, Falcy M, Jarqot D, Pasquier E. Benzène. Fiche ètablie par lês services tecniques et médicaux de L'INRS. Fiche Toxicologique. 2007;49:1-12. [Accès le 15 mars 2016]. Disponible en: http://www.cancer-environnement.fr/Portals/0/ Documents\%20PDF/Rapport/INRS/2004_fiche\%20 tox\%20benz\%C3\%A8ne_INRS.pdf

70. Manini P, De Palma G, Andreoli R, Poli D, Mozzoni P, Folesani G, et al. Environmental and biological monitoring of benzene exposure in a cohort of Italian taxi drivers. Toxicol Lett. 2006;167(2):142-51.

71. Tsin TW. The development and implementation of occupational exposure limits in Hong-Kong. Regul Toxicol Pharmacol. 2006;46(2):114-9.

72. Health Council of the Netherlands. Benzene: health-based recommended occupational exposure limit. The Hague: Health Council of the Netherlands; 2014. (Publication no 2014/03).

73. Environmental Protection Agency. Carcinogenic effects of Benzene: an update (Final). Washington, DC: US Environmental Protection Agency; 1998. (EPA/600/ P-97/001F).

74. World Health Organization. Benzene. In: Air quality guidelines for Europe. $2^{\text {nd }}$ ed. Copenhagen: WHO; 2000. Available from: http://www.euro.who. int/_data/assets/pdf_file/0005/74732/E71922.pdf

75. Park H, Jang JK, Shin JA. Quantitative exposure assessment of various chemical substances in a wafer fabrication industry facility. Saf Health Work. 2011;2(1):39-51.

76. American Conference of Governmental and Industrial Hygienists (ACGIH). Guide for evaluation and control of workplace exposures to chemical substances and physical agents (TLVs) and Biological Exposure Indices (BEIs). $8^{\text {th }}$ ed. California: Signature Publications; 2016. p. 272.

77. Agency for Food Environmental and Occupational Health \& Safety. Opinion: regarding the establishment of a carcinogenic TRV by inhalation for benzene. Maisons-Alfort: ANSES; 2014. p. 1-7. [Cited 2016 mar. 9]. Available from: https://www. anses.fr/fr/system/files/SUBCHIM2009sa0346EN.pdf
78. Scapellato ML, Aprea MC, Moretto A, Bartolucci GB, Manno M. Considerations on the limit values for benzene. G Ital Med Lav Ergon. 2013;35(4):268-71.

79. Arito H. Risk assessment of hazardous substances revisited. Ind Health. 2015;53(3):193-5. [Cited 2016 mar. 9]. Available from: https://www.jniosh.go.jp/ en/indu_hel/doc/IH_53_3_193.pdf

80. Vasconcelos F. Uma visão crítica do uso de padrões de exposição na vigilância da saúde no trabalho. Cad. Saúde Públ. 1995;11(4):588-99.

81. Kim S, Vermeulen R, Waidyanatha S, Johnson BA, Lan Q, Smith MT, et al. Modeling human metabolism of benzene following occupational and environmental exposures. Cancer Epidemiol Biomarkers Prev. 2006;15(11):2246-52.

82. Kim S, Lan Q, Waidyanatha S, Chanock S, Johnson BA, Vermeulen R, et al. Genetic polymorphisms and benzene metabolism in humans exposed to a wide range of air concentrations. Pharmacogenet Genomics. 2007;17(10):789-801.

83. Rappaport SM, Kim S, Lan Q, Li G, Vermeulen R, Waidyanatha S, et al. Human benzene metabolism following occupational and environmental exposures. Chem Biol Interact. 2010;184(1):189-95.

84. Goodson WH III, Lowe L, Carpenter DO, Gilbertson M, Manaf Ali A, Lopez de Cerain Salsamendi A, et al. Assessing the carcinogenic potential of low-dose exposures to chemical mixtures in environment: the challenge ahead. Carcinogenesis. 2015;36(Suppl 1):S254-S296.

85. Chen Y, Li G, Yin S, Xu J, Ji Z, Xiu X, et al. Genetic polymorphisms involved in toxicant-metabolizing enzymes and the risk of chronic benzene poisoning in Chinese occupationally exposed populations. Xenobiotica. 2007;37(1):103-12.

86. Xing C, Marchetti F, Li G, Weldon RH, Kurtovich E, Young S, et al. Benzene exposure near the U.S. permissible limit is associated with sperm aneuploidy. Environ Health Perspect. 2010;118(6):833-9.

87. Ji Z, Weldon RH, Marchetti F, Chen H, Li G, Xing C, et al. Comparison of aneuploidies of chromosomes 21, X, and Y in the blood lymphocytes and sperm of workers exposed to benzene. Environ Mol Mutag. 2012;53(3):218-26.

88. Angelini S, Kumar R, Bermejo JL, Maffei F, Barbieri A, Graziosi F, et al. Exposure to low environmental levels of benzene: evaluation of micronucleus frequencies and $S$-phenylmercapturic acid excretion in relation to polymorphisms in genes encoding metabolic enzymes. Mutat Res. 2011;719(1-2):7-13.

89. Basso E, Cevoli C, Papacchini M, Tranfo G, Mansi A, Testa A, et al. Cytogenetic biomonitoring on a group of petroleum refinery workers. Environ Mol Mutagen. 2011;52(6):440-47.

90. Li L, Li H, Zhang X, Wang L, Xu L, Wang X, et al. Pollution characteristics and health risk assessment of benzene homologues in ambient air 
in the northeastern urban area of Beijing, China. J Environ Sci (China). 2014;26(1):214-23.

91. Corrêa MJM, Mendes JMR. A restrição da exposição ao benzeno no trabalho: uma análise do processo sócio-histórico do movimento de contrapoderes. In: Mendes JMR, Wünsch DS, Camargo M, Monteiro JR, Weizenmann MH, Silva
MG. Saúde e trabalho: múltiplas perspectivas. 1. ed. São Paulo: Plêiade; 2011. p. 175-94.

92. Corrêa MJM. A construção social do silêncio epidemiológico do benzenismo: uma história negada. Porto Alegre. Dissertação [Mestrado em Serviço Social] - Pontifícia Universidade Católica do Rio Grande do Sul; 2008. 